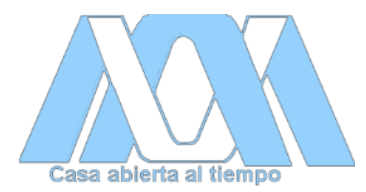

UNIVERSIDAD AUTÓNOMA METROPOLITANA

UNIDAD IZTAPALAPA

División de Ciencias Biológicas y de la Salud

MAESTRÍA EN BIOLOGÍA DE LA REPRODUCCIÓN ANIMAL

\title{
“EFECTO DEL SULFONATO DE PERFLUOROOCTANO PFOS EN LAS UNIONES COMUNICANTES DE LOS COCS PORCINOS DURANTE LA MADURACIÓN IN VITRO (MIV)"'.
}

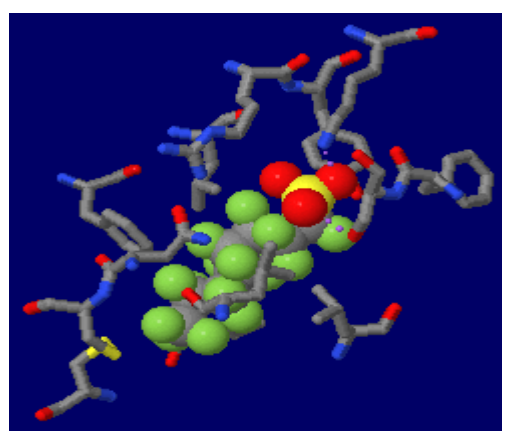

TESIS QUE PARA OPTAR AL GRADO DE MAESTRO EN BIOLOGÍA DE LA REPRODUCCIÓN ANIMAL PRESENTA.

Biol. Exp. Alejandro Domínguez Campuzano ${ }^{1}$.

Directora de Tesis: Dr. Ma. Margarita Zayil Salazar Campos

Asesores: Dr. Edmundo Bonilla González y Dra. Edith Arenas Ríos.

${ }^{1}$ Alumno de la Maestría en Biología de la Reproducción Animal.

Laboratorios de Expresión Génica y Biología Celular. Depto. de Ciencias de la Salud Depto. de Biología de la Reproducción, Universidad Autónoma Metropolitana- Iztapalapa. 


\section{Comité Tutoral}

\section{Director:}

Dra. María Margarita Zayil Salazar Campos.

Profesor Titular

Laboratorio. Expresión Génica S-248.

Departamento. Ciencias de la Salud.

Universidad Autónoma Metropolitana -Iztapalapa

Correo: zayil.salazar@xanum.uam.mx

\section{Asesores}

Dr. Edmundo Bonilla González.

Profesor Titular

Laboratorio. Expresión Génica S248.

Departamento. Ciencias de la Salud.

Universidad Autónoma Metropolitana -Iztapalapa

Correo:mundo@xanum.uam.mx

\section{Dra. Edith Arenas Ríos.}

Profesor Titular

Laboratorio. S-232.

Departamento. Biología de la Reproducción.

Universidad Autónoma Metropolitana -Iztapalapa

Correo: editharenas2000@yahoo.com.mx 


\title{
Jurado
}

\section{Dra. Elizabeth Hernández Pérez}

\author{
Profesor Titular
}

Lab. Farmacología S-348

Depto. Ciencias de la Salud

Universidad Autónoma Metropolitana -Iztapalapa

Correo:sila@xanum.uam.mx

\section{Dr. Marco Alan Pérez Solís}

Unidad de Investigación Médica en Medicina Reproductiva

Hospital de Ginecología y Obstetricia No. 4 IMSS

Correo: marco_perezsolis@yahoo.es 
"El programa de la maestría en Biología de la Reproducción Animal de la Universidad Autónoma Metropolitana (UAMI-I:) pertenece al Padrón de Posgrados de Excelencia del CONACyT (PNPC) registro 003797. 
Este trabajo fue realizado en la Universidad Autónoma Metropolitana Unidad Iztapalapa. Se desarrolló en los siguientes laboratorios: El laboratorio S-248 y S-252 del Departamento de Ciencias de la Salud, bajo la dirección de la Doctora María Margarita Zayil Salazar Campos, y la asesoría del Dr. Edmundo Bonilla González y Dra. Edith Arenas Ríos del laboratorio S-232 del Departamento de Biología de la Reproducción. El alumno Alejandro Domínguez Campuzano recibió apoyo de CONACYT, bajo el número de CVU 508753.

Este trabajo fue financiado por los proyectos: CONACYT 0105961-M y SEP-CONACYT 180043. 
"Los miembros del jurado designado por la División de Biología de la Reproducción, Universidad Autónoma Metropolitana Iztapalapa, abajo firmantes, aprobaron titulada: " Efecto del sulfonato de perfluorooctano (PFOS) en las uniones con la tesis de los COCs porcinos durante la madr

Dr. Edmundo Bonilla González

Presidente

Profesor Titular

Lab. Expresión Génica S-248

Depto. Ciencias Biológicas y de la Salud.

Universidad Autónoma Metropolitana -Iztapalapa

Correo: mundo@xanum.uam.mx

Dra. Edith Arenas Rios

Secretaria

Profesor Titular

Lab. S-232

Depto. de Biología de la Reproducción.

Universidad Autónoma Metropolitana-Iztapalapa

Dra. Flizabeth Hernández Pẹrez

Vocal

Profesor Titular

Lab. Farmacologla S-348

Depto Ciencilas de la Bulud.

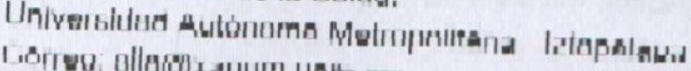

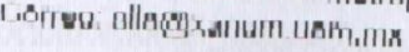

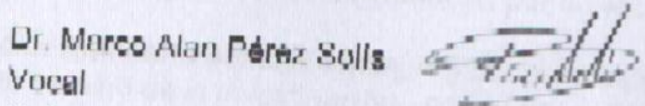

Unidiad de lnvesllgacion Mdation

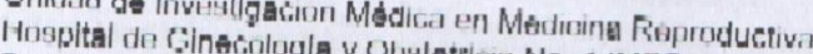

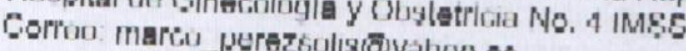
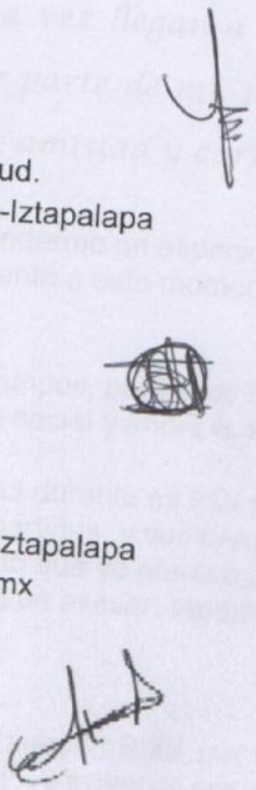


\section{DEDICATORIAS Y AGRADECIMIENTOS}

Son muchas las personas especiales a las que me gustaría agradecer su amistad, apoyo, ánimo y compañía en las diferentes etapas de mi vída. Algunas están aquí conmigo y otras en mis recuerdos y en el corazón. Sín importar en dónde estén o si alguna vez llegan a leer estas dedicatorias quiero darles las gracias por formar parte de mi, por todo to que me han Grindado y por todas sus muestras de amistad y cariño..

Al Doctor Edmundo Bonilla González, por brindarme un espacio en su grupo de investigación, y por ayudarme a llegar finalmente a este momento.

A la Doctora María Margarita Zayil Salazar Campos, por haber batallado conmigo, siendo mi tutor apoyándome durante mi PDI, servicio social y ahora la Maestría.

A la Doctora Edith Arenas Ríos a la cual conocí durante mi PDI por consejo de mi querida amiga Faby, y que a partir de las materias impartidas, y sus preguntas que siempre me hacen pensar y ver que existe mucho más de lo que yo pensaba, me ha brindado su apoyo incondicional, convirtiéndose no solo en un asesor, también algo que pocas veces se logra una excelente amiga.

Muy especialmente, al Doctor José Miguel Betancourt Rule, por todo el apoyo brindado prácticamente desde que yo llegue al laboratorio, y tratarme como un alumno más del laboratorio de Biología Celular, siendo el culpable de que yo pertenezca al S-248 y al S252 y siempre interesarse por mí, llegando a ser hasta ahora, no solo un próximo asesor, un amigo.

A la Doctora Yvonne Ducolomb Ramírez, por su apoyo, sus consejos, y su amistad.

Al Doctor Humberto por sus consejos y observaciones, los cuales me han servido mucho en este camino de la investigación, por su paciencia y apoyo.

A la Doctora María Dolores Saavedra Leos, por haberme dado la oportunidad de trabajar con ella en su proyecto de investigación en mis inicios, sus enseñanzas y su paciencia. 
A Laura Hernández Ponce, si no fuera por ti, nunca habría conocido tantas cosas de la vida, entre ellas aprender a sonreír y a valorar tanto lo que tengo, siempre estarás en mi corazón.

A mis queridos hermanos que nunca tuve, porque de algo estoy seguro algunos hermanos se tienen y otros se eligen: Al próximo maestro Isaac Fernández Gómez, por decirme lo que pocas veces quiero escuchar pero que siempre es necesario y al reciente maestro Mario Teteltitla Silvestre, por siempre mostrarme el valor de la amistad y la humildad, haberme recomendado en este laboratorio para trabajar ya que nunca se me va a olvidar, mi vida eran las plantas.

A mi querida Deisy Hernández Zúñiga por su amistad incondicional, su confianza, y por los viajes esos geniales viajes que siempre recordaré.

A Aracely Salomón García, por su amistad, por siempre brindarme una sonrisa desde que llegó, acompañarme a comer, hacer un buen equipo de trabajo, su apoyo, sus consejos, su confianza, y porque no, un, ale te estoy hablando y palabras de aliento siempre que lo he necesitado.

A la próxima Doctora Indra Victoria Velázquez Ortiz por tener una sonrisa siempre que llego al laboratorio, por brindarme sus consejos, su confianza, su amistad y hacer mis noches más divertidas y geniales acompañándome con un café.

A Iván Bahena Ocampo, A mis profesores de materias optativas que participaron en mi formación, Raul Alva García, Francisco Varona Cordero e Iván Bahena Ocampo por sus enseñanzas, su apoyo, sus consejos y su compañerismo en el laboratorio S-248.

A Ivonne Victoria, por hacer más agradable el tiempo que he estado en el laboratorio con su sonrisa, sus ocurrencias y sus consejos.

A Jackye porque aunque es muy seria, siempre tiene una sonrisa y palabras de aliento cuando las he necesitado, y en poco tiempo se ha ganado mi confianza, siempre recordaré los lunes, miércoles y viernes.

A Lalo y Carlos por su Amistad y sus geniales ocurrencias en el laboratorio.

A Paty Pestañas por haber compartido conmigo sus conocimientos sobre PCR, su paciencia y sus consejos.

A Andy por su apoyo, amistad y sus atinados consejos.

A Graciela, Angie y David, por su amistad y sus consejos. 
A mis amigos del laboratorio de Andrología, Marcos Benito y Lupita por su apoyo.

Especialmente a Diana Martínez Flores, por su apoyo, su amistad, y su paciencia.

A Miriam Casillas Avalos, por el apoyo que siempre me brinda y sus consejos que me han sido de tanta utilidad.

A Almita e Itzel del laboratorio de Biología Celular por su apoyo y compañerismo.

A Olí por brindarme su apoyo y ser una excelente compañera.

A Xiu por tener siempre una sonrisa y regalarme su amistad.

A Ivan Oseguera por su amistad y consejos.

A mis revisores de tesis por sus observaciones y recomendaciones para el mejoramiento de esta.

Al comité de la Maestría en Biología de la Reproducción animal, especialmente al Doctor Pablo por su gran apoyo y paciencia durante estos 2 años.

Como olvidar a Verónica Cruz Taumori, quien siempre que requerí su apoyo, me lo brindo con una sonrisa.

A Trini, porque es una parte muy importante en nuestro trabajo.

Finalmente a mi familia, Mami, estoy seguro de no equivocarme si digo que eres la mejor mama del mundo, gracias por todo tu esfuerzo, apoyo, dedicación, paciencia y la confianza que siempre has depositado en mí, gracias porque siempre aunque estemos lejos, has estado a mi lado.

Papa este es un logro que quiero compartir contigo, gracias por ser mi padre, creer en mí y enseñarme a defenderme siempre.

A mis queridos niños, los gemelos Erick y Fer que están en casa desde los 8 días de nacidos y que me han enseñado tantas cosas de la vida, realmente me siento muy feliz no solo de ser su tío, su amigo.

A mis hermanas, y mi sobrina Cami por sus consejos, su compañía y sus enseñanzas. 
“EFECTO DEL SULFONATO DE PERFLUOROOCTANO PFOS EN LAS UNIONES COMUNICANTES DE LOS COCS PORCINOS DURANTE LA MADURACIÓN IN VITRO (MIV)"........... 1

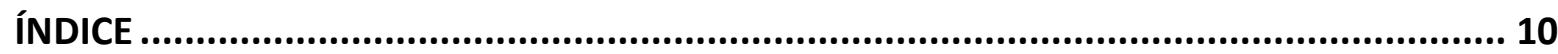

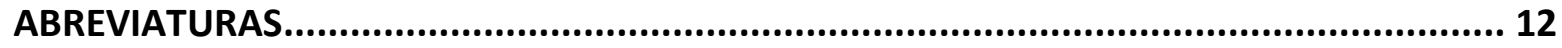

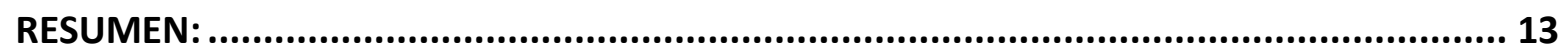

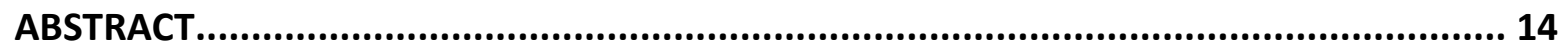

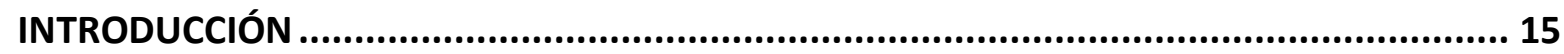

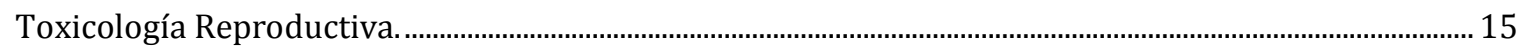

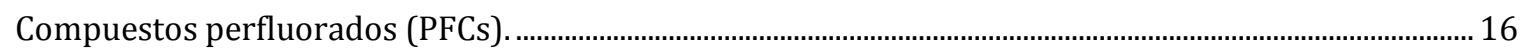

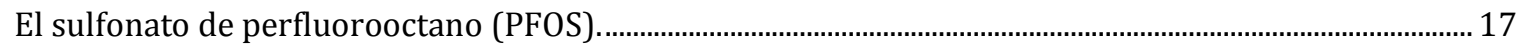

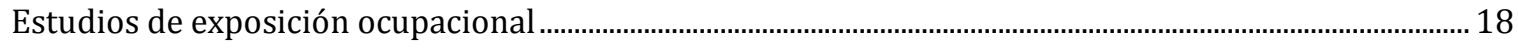

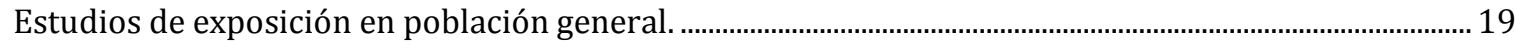

Toxicocinética del PFOS............................................................................................................................................... 19

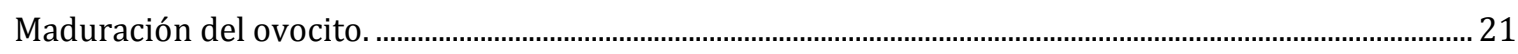

Uniones comunicantes. La importancia del diálogo entre el ovocito y las células del cúmulus............... 23

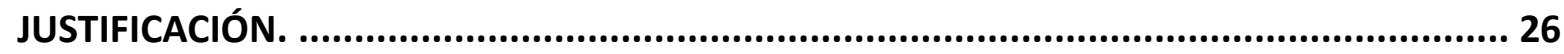

PREGUNTA DE INVESTIGACIÓN.......................................................................... 26

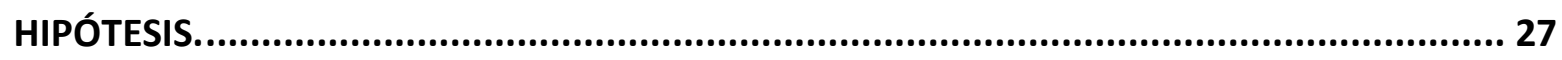




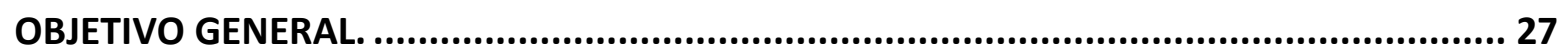

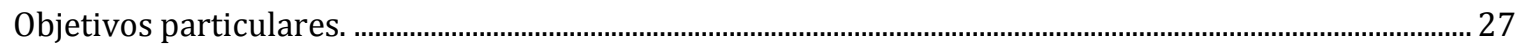

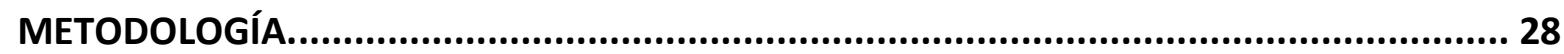

Obtención de COCS y maduración de ovocitos porcinos. ......................................................................................... 28

Viabilidad de ovocitos mediante tinción con azul de tetrazolio (MTT) ....................................................... 29

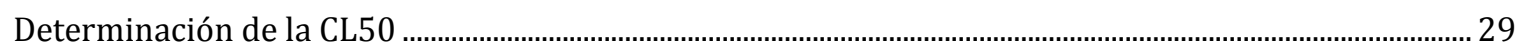

Evaluación de la Maduración de ovocitos mediante tinción con Hoechst ...................................................... 30

Determinación de la CEM50 …………………………......................................................................................... 30

Determinación del efecto de PFOS en las uniones intercelulares comunicantes y en la maduración de

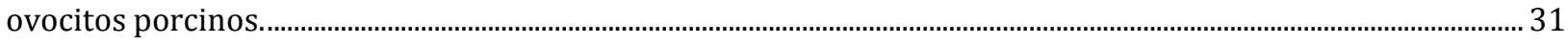

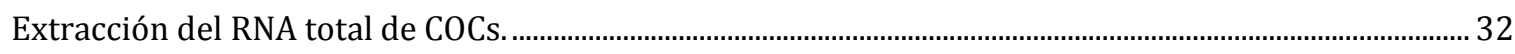

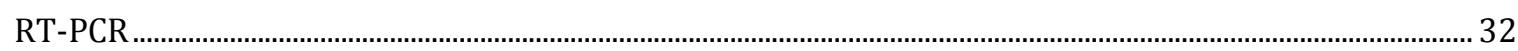

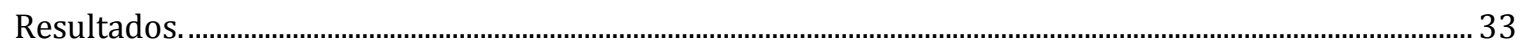

Determinación de la viabilidad con el diluyente durante la maduración de ovocitos. ................................33

Determinación de la CL50 de PFOS durante la maduración de ovocitos......................................................34

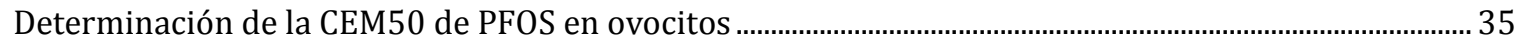

Evaluación de $10 \mu \mathrm{M}$ de PFOS en las uniones comunicantes a diferentes tiempos de incubación........... 37

Análisis de expresión Génica de las Conexinas 43, 45 y 60 en COCs Porcinos............................................42

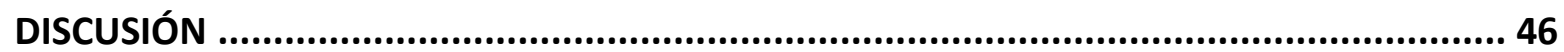

Determinación de la viabilidad con el diluyente durante la maduración de ovocitos ................................. 46

Determinación de la CL50 de PFOS durante la maduración de ovocitos.......................................................47

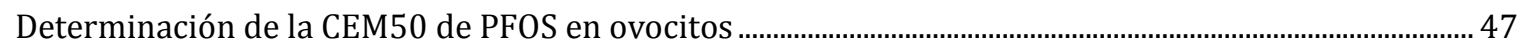

Efecto de la CEM50/2 de PFOS en las uniones comunicantes en diferentes tiempos de incubación ....48

Análisis de Expresión Génica de las Conexinas 43, 45 y 60, a las 4.5, 8.5 y 44h.......................................49

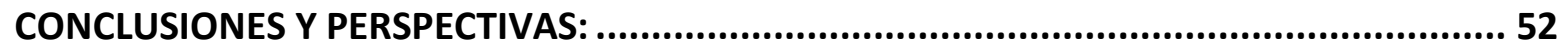

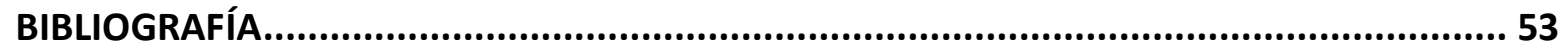

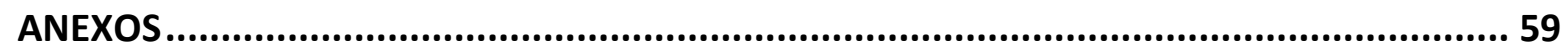

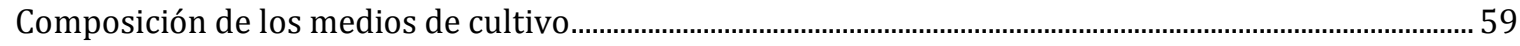




\section{ABREVIATURAS}

COCs Complejo ovocito-células del cúmulo.

MIV Maduración in vitro

Cx43 Conexina 43

Cx45 Conexina 45

Cx60 Conexina 60

CBX Carbexonolona di sódica.

MTT Metil-tiazolil-difenil-tetrazolio.

Hoechst Bisbenzimide H33342 trihydrochloride

PFOS Sulfonato de perfluorooctano.

CEM$_{50}$ Concentración efecto en la maduración ${ }_{50}$

COFs Compuestos orgánicos fluorados

$\mathrm{CL}_{50} \quad$ Concentración letal ${ }_{50}$ 


\section{Resumen:}

EI PFOS es un compuesto perfluorado ampliamente utilizado como surfactante ya que sus propiedades fisicoquímicas lo hacen resistente al calor y repelente al agua, al aceite y a la tinción. Sin embargo, debido a su presencia en sangre y órganos internos de organismos que no han sido expuestos directamente y a su ubicuidad en el ambiente, se le ha asociado con ciertas patologías como el cáncer y la disminución de la fertilidad.

Existen estudios en células somáticas que indican que el PFOS, entre otros efectos, inhibe la comunicación intercelular de tipo hendidura, y ya que se han reportado niveles de diferentes PFCs en el líquido folicular humano, el objetivo de este estudio fue determinar si el PFOS tiene un efecto en la comunicación tipo hendidura durante el proceso de maduración del ovocito, utilizando como modelo COCs porcinos. Con el fin de obtener información acerca de los mecanismos moleculares del posible daño de PFOS en las uniones de hendidura, se analizó su efecto en la expresión de las Cx43, CX45 y CX60 durante la maduración de ovocitos de cerdo in vitro.

En este estudio, la concentración letal $50\left(\mathrm{CL}_{50}\right)$ para ovocitos fue de $29 \mu \mathrm{m}$, y la concentración de efecto en la maduración 50 in vitro $\left(\mathrm{CEM}_{50}\right)$ fue de $23 \mu \mathrm{M}$, lo que indica que la población ocupacionalmente expuesta a PFOS está en riesgo ya que estas concentraciones son muy similares a las encontradas en el plasma sanguíneo de esta población. Cuando los COCs fueron madurados usando un medio de la concentración de efecto en la maduración50 $\left(\mathrm{CEM}_{50}\right)$, se observó que el PFOS inhibe las uniones comunicantes y la maduración meiótica del ovocito. 
En este estudio se observó que el PFOS no altera la expresión de RNAm de las Cx45, Cx43, y CX60 lo que aparentemente indica que el PFOS no afecta a nivel genómico. Estos hallazgos indican la necesidad de comprobar los mecanismos mediante los que PFOS inhibe la maduración meiótica, sin olvidar el estudio de las modificaciones post-traduccionales de las conexinas ya que estas son cruciales en la señalización para iniciar el proceso de maduración nuclear.

\section{Abstract}

Perfluorooctane sulfonate (PFOS) is a persistent and bio-accumulative pollutant ubiquitous in wildlife and humans, which receives many concerns on its fate, transport, distribution, and toxicity. There is a concern about its presence in human blood and internal organs which points toward associations with multiple human health endpoints including fertility. Researches have shown that PFOS inhibits Gap Junction Communications (GJC), and as levels of PFCs are found in human follicular fluid it might have a deleterious effect on fertilization rates.

The aim of this study was to determine whether PFOS has an effect on GJC during oocyte maturation using as a model in vitro matured porcine oocytes. In order to get information about the molecular mechanisms of injury by PFOS, its effect on the RNA expression of $\mathrm{C} \times 45, \mathrm{C} \times 43$ and $\mathrm{C} \times 60$ was analysed at $4.5 \mathrm{~h}, 8.5 \mathrm{~h}$ and $44 \mathrm{~h}$ in oocytes matured in vitro.

The Lethal Dose $_{50}$ (LD50) for oocytes was $29 \mu \mathrm{M}$, and the Inhibition of In vitro Maturation $_{50}\left(\mathrm{IVM}_{50}\right)$ was $23 \mu \mathrm{M}$, thus indicating that the population occupationally exposed to PFOS is at risk since this concentration is very similar to that found in the plasma of plant workers. When COCs were matured at the $\mathrm{IVM}_{50}$, it was observed that PFOS inhibits Oocyte calcein uptake through gap junctions; In addition, the Meiotic Maturation of oocytes was inhibited. However, PFOS did not alter Cx45, Cx43, and Cx60 RNA expression, which apparently indicate that it does not affect at the genomic level. These findings indicate the need to check the interference of PFOS in the meiotic 
maturation pathways, and also revise the connexin post-translational modifications, since these are crucial in the signalling to start the nuclear maturation process.

\section{Introducción}

Desde 1950, la producción de compuestos químicos que incluyen insecticidas, herbicidas, y surfactantes se ha incrementado. Estos agentes exógenos se conocen como xenobióticos y dado que su producción ha ido en aumento, se les ha asociado con daños en el ambiente y con la salud de personas que se exponen directa 0 indirectamente a éstos. La presencia de xenobióticos en plasma de humanos en todo el mundo ha motivado la investigación de sus efectos en numerosos estudios (Eriksen et al., 2013).

Numerosos reportes asocian la presencia de xenobióticos con daños a diferentes niveles: desde cromosómicos, hasta organismo; y en los organismos superiores, entre sus blancos se encuentran el hipotálamo, la tiroides, hígado etc. Por otra parte, a nivel reproductivo se asocia el uso y presencia de los xenobióticos en el ambiente con disfunciones que van desde el comportamiento hasta problemas de fertilidad (Governini et al., 2011).

\section{Toxicología Reproductiva.}

Es la rama de la toxicología que se encarga del estudio de los efectos deletéreos producidos por agentes exógenos en la reproducción. Existe información sobre los efectos agudos de los xenobióticos, pero los efectos crónicos son menos conocidos.

Uno de los enfoques de la toxicología reproductiva es el estudio de los efectos deletéreos en el sistema reproductivo durante las distintas etapas de desarrollo, ya que estos pueden suceder durante los periodos, prenatal o postnatal, y afectar entre otros procesos la gametogénesis. 


\section{Compuestos perfluorados (PFCs).}

Los compuestos organofluorados contienen átomos de carbono y flúor unidos mediante enlaces covalentes y notablemente polarizados.

Los PFCs se subdividen en dos categorías:

-Perfluoroalquil-sulfonatos, entre los que se encuentran el ácido perfluorohexano sulfónico ( $\mathrm{PFHxS}$, con fórmula $\left.\mathrm{CF}_{3}-(\mathrm{CF} 2) 5-\mathrm{SO}_{3} \mathrm{H}\right)$ y el ácido perfluorooctano sulfónico (PFOS, con fórmula $\left.\mathrm{CF}_{3}-\left(\mathrm{CF}_{2}\right)_{7}-\mathrm{SO}_{3} \mathrm{H}\right)$.

-Perfluoroalquil-carboxilatos, entre los que se encuentra el ácido perfluorooctanoico (PFOA, con fórmula $\left.\mathrm{CF}_{3}-\left(\mathrm{CF}_{2}\right)_{6}-\mathrm{COOH}\right)$ y el ácido perfluorodecanoico (PFDA, con fórmula $\left.\mathrm{CF}_{3}-\left(\mathrm{CF}_{2}\right)_{8}-\mathrm{COOH}\right)$.

Tanto los Perfluoroalquil-sulfonatos como los Perfluoroalquil-carboxilatos son compuestos persistentes en el ambiente (COPs) y bioacumulables ya que poseen características de toxicidad capaces de ocasionar efectos adversos a la salud o al ambiente (Fei et al., 2009).

Se estima que la producción total de perfluoroalquil-sulfonatos de 1970 a 2002 fue de aproximadamente 100,000 toneladas (Paul et al., 2009), y aunque la producción de Perfluoroalquil-sulfonatos se suspendió por la compañía 3M en EUA, su presencia aún es elevada y se estima que su producción en China durante 2006 fue de más de 200 toneladas, mientras que la producción de Perfluoroalquil-carboxilatos para ese mismo año fue de 9 mil toneladas (US EPA 2006).

Son diversos los estudios que demuestran los efectos deletéreos de los PFCs. Por ejemplo, durante el desarrollo de ratones se demostró que se alteran las funciones de la inmunidad innata y humoral (Johansson et al., 2009). También afectan la homeostasis de calcio y la función mitocondrial, procesos fisiológicos que cuando son 
alterados, pueden desencadenar apoptosis (Kleszczynski y Skladanowski, 2011). Por otro lado, en células somáticas está bien documentado que diferentes PFCs interfieren con las uniones intercelulares comunicantes, también llamadas de hendidura o gap dependiendo del tamaño de la cadena del compuesto químico (Upham et al., 2009). Además, pueden producir proliferación de peroxisomas, hepatomegalia, hiperplasia y hepatocarcinogénesis (Keil et al., 2008; Sohlenius et al., 1994).

\section{El sulfonato de perfluorooctano (PFOS).}

El PFOS consta de una cadena de ocho átomos de carbono en el que los átomos de hidrógeno han sido reemplazados por átomos de flúor y por un grupo $\mathrm{SO}_{2} \mathrm{O}^{-}$para formar una estructura aniónica estable, que a su vez, puede formar una sal hidrosoluble y cristalina con metales como el litio, el sodio o el potasio, o con otros grupos catiónicos como el $\mathrm{NH}_{4}{ }^{+}$(CESE 2006) Figura 2.

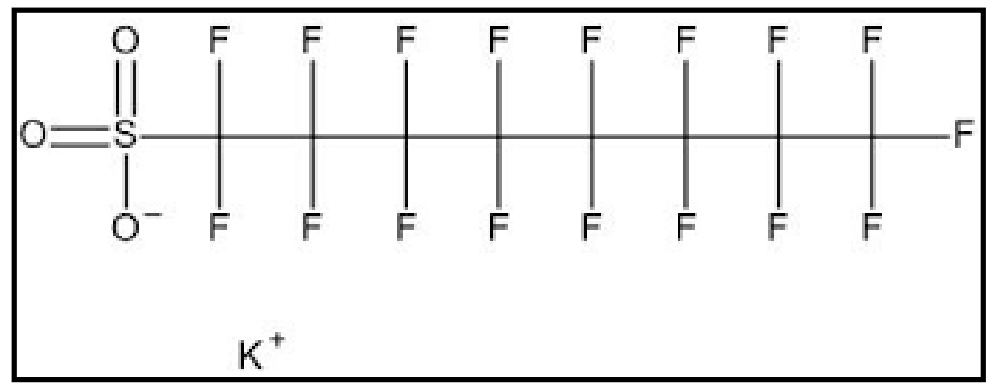

Figura 2. Modelo estructural de la molécula de PFOS, la cual para hacerla más soluble. Se utiliza como sal de potasio. (CESE 2006).

La combinación de sus propiedades orgánicas (basadas en el carbono, solubles en aceite) e inorgánicas (sal metálica, hidrosoluble) hace que las sustancias relacionadas con los PFOS sean altamente eficaces como agentes activos sobre las superficies (surfactantes) en una gama de aplicaciones especializadas. Además, EI PFOS resiste la oxidación, es inerte, incombustible y estable a cualquier otro tipo de descomposición, por 
lo que cuando se libera al ambiente es persistente y debido a su solubilidad tanto en aceite como agua es bioacumulable (CESE 2006).

La afinidad de PFOS por la albúmina tiene implicaciones que incluyen su transporte a través del plasma a diferentes tejidos y órganos, que aunado a la estabilidad de su estructura lo convierten en un compuesto bioacumulable y que tarda en excretarse, desde el 2002 se reportó que uno de los efectos del PFOS es que puede inhibir las uniones tipo gap de manera comparable a la del PFDA, el inhibidor de uniones comunicantes más potente de los ácidos perfluorinados (Luo et al., 2012; Zhang et al., 2013; Zhang et al., 2009). Se señala también, que PFOS produce la inhibición de las uniones comunicantes formadas por CX43, y Cx32/Cx26, sugiriendo el potencial de este compuesto para alterar las uniones comunicantes en diferentes tejidos y organismos. También se menciona que la inhibición de uniones comunicantes por PFOS es proporcional a su concentración y reversible (Hu et al., 2002).

En otros estudios, se reporta que PFOS tiene efectos en el desarrollo incluyendo reducción del peso fetal, mayor incidencia en la aparición de paladar hendido, anasarca (edema), retrasos en la osificación (esternón y falanges) y anormalidades cardiacas (defecto ventricular septal y dilatación de la aurícula derecha). Sin embargo, es importante recalcar que la mayoría de estas anormalidades estructurales se han observado en animales expuestos a las dosis más elevadas de PFOS tales como $10 \mathrm{mg} / \mathrm{kg}$ de peso (Austin et al., 2003; Lau et al., 2004).

\section{Estudios de exposición ocupacional}

Los datos de investigación en personal ocupacionalmente expuesto indican que la media de concentración de PFOS en sangre de personas que trabajan en la producción de fluoroquímicos depende de la tarea realizada dentro de la planta, y las concentraciones son: sin exposición directa al lugar de trabajo de fluoroquímicos basados en el PFOS $(0,11-0,29 \mu \mathrm{g} / \mathrm{ml})$, en un bajo potencial de exposición laboral a 
productos químicos fluorados basados en el PFOS $(0,39-0,89 \mu \mathrm{g} / \mathrm{ml})$, y de alto potencial de exposición laboral a productos químicos fluorados basados en el PFOS (1.30$1,97 \mu \mathrm{g} / \mathrm{ml}$ ) o entre 500-2000ng/ml (Alexander y Olsen, 2007; Olsen et al., 2003b).

Un estudio realizado con trabajadores de una planta de PFOS y sustancias relacionadas, reveló que no existía una mayor prevalencia de enfermedades hepáticas (incluyendo tumores), cáncer de vejiga, trastornos en el metabolismo tiroideo y lipídico. En cambio, sí se observó una mayor incidencia de trastornos en el tracto biliar, cistitis, pólipos benignos en el colon, tumores malignos colorectales, y melanoma maligno (Olsen et al., 2007).

\section{Estudios de exposición en población general.}

Una serie de estudios en la población general, ha mostrado la existencia de concentraciones de PFOS en muestras de personas no expuestas (Ericson et al., 2007). Las muestras incluyen sangre del cordón umbilical y sangre materna (Inoue et al., 2004; Midasch et al., 2007), leche materna (Karrman et al., 2007), plasma (Guruge et al., 2005), y tejido hepático (Olsen et al., 2003a).

La gran mayoría de los datos existentes sobre las concentraciones de PFOS en sangre humana provienen de estudios realizados en Estados Unidos y Japón (Butenhoff et al., 2006).

\section{Toxicocinética del PFOS.}

Estudios toxico cinéticos realizados en animales indican que el PFOS es rápidamente absorbido, distribuido y acumulado en plasma e hígado, encontrando que las concentraciones de PFOS en hígado pueden ser varias veces más elevadas que en sangre (Seacat et al., 2003; Seacat et al., 2002). De hecho, el hígado parece ser el órgano diana de esta sustancia (Butenhoff et al., 2006). A diferencia de otros COPs 
(compuestos orgánicos persistentes), clorados y bromados, el PFOS no se acumula en grasas (Lau et al., 2004). La razón de este fenómeno es que el PFOS es anfipático y se une preferentemente a proteínas del plasma, como la albúmina (Zhang et al., 2009).

\section{Estudios de vida media.}

Por otro lado, existen estudios que indican que la tasa de eliminación del PFOS es muy baja. Por ejemplo, se ha estimado que su vida media en el organismo de ratas macho es de más de 90 días hasta que es eliminado a través de la orina y las heces (Seacat et al., 2003). En otro estudio se determinó que en plasma de ratas su vida media es de 7.5 días tras un tratamiento vía oral y de aproximadamente 100-200 días en monos Cynomolgus, tanto machos como hembras, después de un tratamiento con una duración de 6 meses (Seacat et al., 2002).

Sin embargo en humanos, los análisis realizados en suero de trabajadores de una planta de producción de PFOS mostraron que este contaminante cuenta con una vida media de aproximadamente 5 años (Olsen et al., 2007). Estos datos sugieren que existen diferencias en la cinética de la eliminación del PFOS entre especies (Harada et al., 2005). 


\section{Maduración del ovocito.}

Durante la maduración del ovocito en el folículo, este sufre una serie de cambios bioquímicos y morfológicos que lo preparan para llevar a cabo la fertilización y desarrollo embrionario adecuados. Los cambios más aparentes e importantes son la formación de un núcleo haploide y un aumento de tamaño debido al material acumulado en su citoplasma. En este proceso el ovocito mantiene una relación íntima con las células de la granulosa que lo rodean a través de uniones comunicantes y esta relación es necesaria para establecer una cooperatividad metabólica entre los dos tipos de células (Figura 3). Antes que el ovocito sea madurado, permanece en un arresto meiótico en la profase 1. Durante este periodo a través de una serie de procesos de maduración, citoplásmicos y nucleares el ovocito adquiere su competencia para ser fertilizado y sustentar el desarrollo embrionario. El momento en el que alcanza su completo desarrollo está determinado por las señales de retroalimentación bidireccional que suceden entre el ovocito y sus células acompañantes, las células del cúmulus.

Las células del cúmulus, que rodean al ovocito, lo van a mantener en un arresto meiótico hasta que reciben la señal de la LH que induce la producción de proteínas del tipo del factor de crecimiento en las células murales de la granulosa, las cuales a su vez actúan en las células del cúmulus que dispararan la maduración del ovocito(Conti et al., 2012).

Un aspecto clave en la adquisición de la competencia del ovocito y su progresión en la meiosis es la organización de la cromatina. Se sabe que una de las principales causas por las que el ovocito permanece en arresto meiótico es debido al suministro de AMPc por las células del cúmulus a través de las uniones comunicantes (Conti et al., 2012; Sasseville et al., 2009; Sela-Abramovich et al., 2005; Thomas et al., 2004). De hecho, los niveles del AMPc dentro del ovocito son controlados por diversos factores que incluyen la velocidad de síntesis y metabolismo en cada compartimento del folículo, y el 
mantenimiento del transporte a través de las uniones comunicantes de las células del cúmulus al ovocito (Figura 4). Cuando la gonadotropina provoca un incremento del AMPc en las células del cúmulus entonces cesa la comunicación de estas con el ovocito debido a que las conexinas de las uniones comunicantes son fosforiladas y su síntesis disminuye de tal manera que en el ovocito los niveles de AMPc bajan y se promueve el reinicio de la meiosis (Russell|y| Robker, 2007). Experimentos realizados en ovocitos murinos indican que si las uniones comunicantes son bloqueadas con CBX (Carbenoxolona) durante las primeras 5 horas de cultivo los ovocitos maduran, y que de hecho desde las primeras 2 horas ya hay índices de maduración, es decir, si las uniones comunicantes se bloquean el ovocito madurará (Sela-Abramovich et al., 2006).

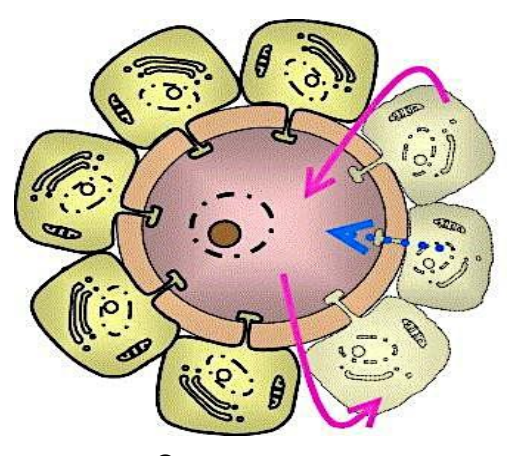

3

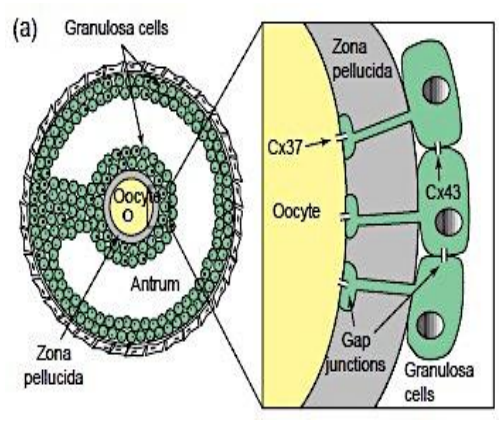

4

Figuras 3 y 4 . Modelo que representa las interacciones ovocito-células del cúmulus. Se muestra el flujo de señales tanto parácrinas, autocrinas, y yuxtacrinas que implican un continuo intercambio de información mediado por uniones comunicantes (conexinas), para que sucedan procesos como la maduración del ovocito y del folículo. Tomadas de (Gilchrist et al., 2004) 


\section{Uniones comunicantes. La importancia del diálogo entre el ovocito y las células}

del cúmulus.

Ya se ha mencionado que en los folículos ováricos, la comunicación intercelular mediada entre el ovocito y las células somáticas que lo acompañan es crítico para el desarrollo de ambos compartimentos foliculares.

El contacto entre las células somáticas y el ovocito es mediado por las uniones comunicantes, que son conjuntos de canales de membrana intercelular que permiten a las células adyacentes compartir moléculas pequeñas $(<1 \mathrm{kDa})$. Estos canales se componen de hexámeros de conexinas (Cxs), una familia homóloga de más de 20 proteínas. Cada conexina contiene dominios altamente conservados, así como dominios divergentes que les confieren propiedades únicas (Goldberg et al., 2004). Asimismo cada conexina posee un perfil de expresión específico y aunque algunas conexinas se expresan de manera ubicua, otras se limitan a tejidos, células y momentos o señales específicas (Cruciani y Mikalsen, 2006; Santiquet et al., 2013).

En los ovarios de los mamíferos se han detectado 8 conexinas diferentes (Kidder|y| Mhawi, 2002). En los COCs del ratón, la comunicación entre las células de la granulosa está mediada principalmente por Cx43, mientras que la comunicación entre el ovocito y las células del cúmulus es principalmente a través de la Cx37 (Gilchrist et al., 2008)(figura 4), y se ha reportado que la mutación del gen para Cx37 elimina la producción de folículos de Graff y el desarrollo del ovocito (Carabatsos et al., 2000). El hecho de que los canales de Cx43 y Cx37 posean diferente permeabilidad y que sus placas no se sobrelapen corrobora que cada conexina desempeña un papel en lugares y tiempos específicos. Así también se ha visto que la Cx43 es detectable en las células de la pre granulosa en el folículo primordial, probablemente mediando la relación entre las células somáticas (Gittens y Kidder, 2005). Conforme el folículo se desarrolla, el número de uniones de Cx43 aumenta especialmente en la transición de folículo 
preantral a antral. Si la Cx43 no se expresa, la foliculogénesis se arresta en el estado unilaminar (Gittens y Kidder, 2005).

En el porcino, se han identificado 3 Conexinas principales que participan en la comunicación del ovocito y las células de la granulosa, la Cx43 que se expresa mayormente en las células del cúmulus, la $\mathrm{C} \times 45$ que se expresa tanto en células de la granulosa y el ovocito y la Cx60 que sólo se expresa en el ovocito (Santiquet et al., 2013). Sin embargo, el contacto entre las células foliculares no debe ser considerado como una estructura permanente sino más bien como una estructura que se adapta continuamente en respuesta a la actividad, tanto de las células de cúmulus, como del ovocito. Tal es la importancia de la cooperación metabólica entre los ovocitos y las células de cúmulus que la glucosa que es metabolizada a piruvato en las células del cúmulus es transferida al ovocito para que este realice sus procesos generadores de energía (Wang et al., 2012). Igualmente, parte del colesterol sintetizado en las células del cúmulus es transferido al ovocito dada la incapacidad de esta célula para producir o tomar el lípido del exterior (Su et al., 2009). Por su parte, el ovocito regula la proliferación de células de la granulosa e induce la expresión del fenotipo diferencial a células murales y del cúmulus mediante señales hormonales induciendo una alta expresión de RNAs en las células del cúmulus (Su et al., 2009).

La expansión de las células del cúmulus requiere de la presencia del ovocito ya que células aisladas del cúmulus son incapaces de responder al estímulo de la FSH y formar una matriz expandida. Genes tales como Ptgs2, que codifica a la prostaglandinaendoperóxido sintetasa2 (COX-2), hialuron sintetasa 2 (HAS-2) y el factor de necrosis inducido por la proteína 6 (TNFAIP6/TSG-6) que tienen un papel esencial en la expansión celular son estimulados por la presencia de gonadotrofinas y de factores secretados por el ovocito (Dragovic et al., 2005; Gilchrist et al., 2004; Hussein et al., 2006; Sugiura et al., 2010). En folículos de rata GDF-9 y BMP-15, que se sintetizan en el ovocito junto con el estradiol- $\beta 17$ coordinan el desarrollo de las células del cúmulus y su expansión (Gilchrist et al., 2004; Sugiura et al., 2010). Sin embargo, en otros 
mamíferos (porcinos, equinos y bovinos), se ha visto que la expansión de las células del cúmulus está regulada por factores producidos por las propias células somáticas en vez del ovocito (Liang et al., 2005; Prochazka et al., 1998). Por lo anterior, entender los mecanismos que se realizan por la estimulación de las gonadotrofinas en la comunicación regulada por las uniones intercelulares es fundamental para entender los mecanismos que regulan la maduración del ovocito(Sasseville et al., 2009).

Respecto a los COCs porcinos, se ha reportado que las células del cúmulus sobreexpresan $\mathrm{C} \times 43$ cuando son separados de las células de las células murales. Además, la expresión y reclutamiento de conexinas en uniones comunicantes es independiente de la señal de la godanotrofina, aunque la expansión y ruptura de las uniones comunicantes es un mecanismo dependiente de la gonadotrofina e incluye el reclutamiento de Cx43 en microdominios lipídicos (Sasseville et al., 2009). Por otra lado, Nitta et al. (Nitta et al., 2010) mencionan que la expresión de las conexinas es espacio temporal. Además, determinan que las conexinas que más se expresan durante la maduración del folículo porcino son los correspondientes a Cx45 y Cx60. Identifican a la Cx60 en la interfase entre el ovocito y las células del cúmulus mientras que la Cx45 se detectó en ovocitos, pero no en las células cúmulo, sugiriendo un perfil diferente y función para cada conexina durante la ovogénesis y la foliculogénesis. Además, reportan no encontrar expresión de la Cx37 en la superficie del ovocito en ninguna de las etapas estudiadas. En estudios anteriores ya reportan la presencia de $\mathrm{Cx} 43$ y suponen la formación de canales mediante Cx43 y Cx45 dada su compatibilidad al igual que los canales heterotípicos formados por $\mathrm{C} \times 60$ y $\mathrm{C} \times 43$ que parecen ser compatibles y formar canales funcionales (Thomas et al., 2004). 


\section{Justificación.}

Los compuestos perfluorados pueden afectar los sistemas reproductivos, producir daño genético, causar infertilidad, malformaciones, abortos espontáneos, etc. Incluso en población no expuesta. Hasta el momento, la mayor parte de los reportes del efecto de los PFC's a nivel reproductivo se enfoca en órganos masculinos, gametos masculinos y como disruptor endócrino, pero también se relaciona con una disminución en la fertilidad femenina.

Se sabe que en la maduración del ovocito existen cascadas de regulación génica y señalización que son especialmente sensibles a la exposición por xenobióticos. Diferentes estudios demuestran la presencia de PFOS en ovarios de rata, y en el fluido folicular de humanos. Sin embargo, hasta el momento no existe algún reporte de su efecto en la maduración del ovocito. Se sabe que las uniones comunicantes son esenciales para el desarrollo del folículo y la maduración del ovocito y puesto que está documentado el daño que este perfluorado ocasiona en uniones comunicantes de células somáticas, en este trabajo se propone analizar si PFOS interfiere en las uniones intercelulares comunicantes durante la maduración de ovocitos en un modelo in vitro.

\section{Pregunta de investigación.}

¿Tiene PFOS algún efecto en las uniones comunicantes de los COCs, y por lo tanto en la maduración de ovocitos porcinos in vitro? 


\section{Hipótesis.}

En células somáticas PFOS afecta las uniones comunicantes. Estas uniones son muy importantes para la maduración del ovocito, por lo que si las uniones existentes entre el ovocito y las células de la granulosa se ven afectadas, también se verá afectado el proceso de maduración.

\section{Objetivo general.}

Determinar si el efecto de PFOS en las uniones comunicantes repercute en la maduración de ovocitos porcinos.

\section{Objetivos particulares.}

Determinar la concentración letal (CL50) y de efecto en la maduración (CEM50) en el ovocito.

Evaluar con calceína si la CEM50/2 de PFOS inhibe las uniones intercelulares comunicantes de los COCs durante la MIV.

Analizar la expresión de los genes de las conexinas Cx43, Cx45 y Cx60 durante la maduración de los COCs expuestos a la CEM50/2 de PFOS. 


\section{Metodología.}

Todos los reactivos utilizados fueron de la marca Sigma (Sigma chemical Company, St Louis, MO EUA). Los reactivos y las soluciones se esterilizaron mediante filtración con membranas de $0.22 \mu \mathrm{m}$ Millex-GV (Millipore). Todas las técnicas se realizaron bajo condiciones de esterilidad en campana de flujo laminar (Veco, Mexico). Los procedimientos de MIV se realizaron sin cubrir con aceite mineral. Después de su preparación los medios empleados se conservaron a $4^{\circ} \mathrm{C}$, y si no eran usados después de 21 días, eran desechados.

\section{Obtención de COCS y maduración de ovocitos porcinos.}

La maduración in vitro (MIV) de ovocitos porcinos se realizó de acuerdo con el método reportado por Abeydeera y Casas (Abeydeera et al., 1998; Casas et al., 2010). Se colectaron ovarios de cerdas prepúberes en el rastro, justo después de que los animales fueron sacrificados. Los ovarios, se transportaron al laboratorio en solución salina $0.9 \%$, a $38^{\circ} \mathrm{C}$.

Los COCs en fluido folicular se recuperaron por punción a partir de folículos de 3 a $6 \mathrm{~mm}$ de diámetro a través de vacío con jeringa de $10 \mathrm{ml}$ y aguja de $18 \mathrm{G} \times 38 \mathrm{~mm}$ y se dejaron sedimentar. Bajo el microscopio se seleccionaron aquéllos COCs en los que los ovocitos aparecían rodeados por una masa folicular compacta y presentaban un citoplasma granular regular. Estos COCs fueron lavados 3 veces en medio de maduración TCM-199 con Bicarbonato y sales de Earle (In Vitro México) suplementado con PVA $0.1 \%$, Glucosa $3.05 \mathrm{mM}$ y Piruvato de sodio $0.91 \mathrm{mM}$, cisteína $0.57 \mathrm{mM}$ y EGF (Factor de crecimiento epidérmico) $10 \mathrm{ng} / \mathrm{ml}$ ) para posteriormente colocar de 30 a 35 COCs por pozo en una gota de $500 \mu \mathrm{l}$ con el mismo medio y suplementado con las hormonas Folículo estimulante y Luteinizante (FSH y LH). El medio había sido equilibrado 
previamente con $\mathrm{CO}_{2}$ al $5 \%$ en una incubadora a $38.5^{\circ} \mathrm{C}$ y humedad a saturación. Para que la maduración de los ovocitos seleccionados sucediera, se dejaron pasar de 44 a 48 horas en incubación en las mismas condiciones.

\section{Viabilidad de ovocitos mediante tinción con azul de tetrazolio (MTT).}

Posterior a la maduración y eliminación de las células del cúmulus los ovocitos, se colocaron en otra caja de 4 pozos, donde se cubrieron con $200 \mu \mathrm{L}$ de MTT $(0.5 \mathrm{mg} / \mathrm{mL})$ y se incubaron durante 90 minutos.

La viabilidad de los ovocitos se evaluó bajo un microscopio estereoscópico (Olympus SZ60, Olympus Optical, Japón) a 400 aumentos. Se consideraron vivos a los ovocitos que presentaron una coloración púrpura y muertos los que no presentaron color.

\section{Determinación de la CL50}

Para determinar la CL50, los complejos ovocitos-células del cúmulus se incubaron con diferentes concentraciones, (control, control solvente DMSO, 12.5, 25, 50 $\mu \mathrm{M}$ de PFOS en medio TCM-199). Después de 44h de incubación los ovocitos se denudaron y se lavaron con PBS.

Como se indicó líneas arriba para medir la viabilidad, los ovocitos se incubaron en bromuro de metiltiazolidifenil de tetrazolio (MTT) $0.5 \mathrm{mg} / \mathrm{ml}$ de acuerdo a la metodología reportada por Casas et al. (Casas et al., 2010). La CL50 se determinó utilizando regresión lineal binomial Probit, incluida en el paquete estadístico SPSS (FDA,USA) y los gráficos se realizaron utilizando el paquete estadístico Origin Lab 9. 


\section{Evaluación de la Maduración de ovocitos mediante tinción con Hoechst}

Posterior a la tinción con MTT para remover el exceso de éste, los ovocitos se lavaron en gotas de $500 \mu \mathrm{L}$ de PBS, mediante 2 ó 3 resuspensiones. Los ovocitos se colocaron en otra caja y se cubrieron con $200 \mu \mathrm{L}$ de Hoechst (3342) $(45 \mu \mathrm{g} / \mathrm{mL})$ en PBS. Se dejaron durante 45 minutos en oscuridad a $4^{\circ} \mathrm{C}$. Posteriormente, los ovocitos se lavaron en gotas de 500 $\mu \mathrm{L}$ de PBS, con 2 ó 3 resuspensiones para eliminar el exceso de Hoechst, y se colocaron en otra caja con $500 \mu \mathrm{L}$ de fijador con PBS (glutaraldehído $50 \mu \mathrm{L} / 5 \mathrm{~mL}$ ), durante 20 minutos a temperatura ambiente y oscuridad.

Posteriormente, 15 ovocitos aproximadamente fueron transferidos a un portaobjetos con

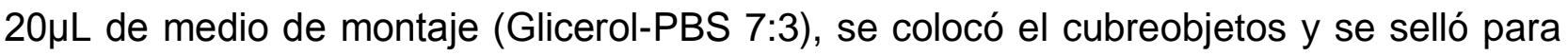
su observación.

La evaluación de la maduración de los ovocitos se llevó a cabo a 400 aumentos, utilizando un microscopio Zeiss, modelo Axioscop y filtro de fluorescencia con rango de excitación para luz ultravioleta (482 nm).

De acuerdo a las características observadas, los ovocitos se clasificaron en: Inmaduros para aquellos que mostraron vesícula germinal (VG), en vías de maduración para los que presentaron cromosomas en Metafase I (MI) y Maduros para aquellos con cromosomas y el primer cuerpo polar en extrusión Metafase II (MII) (Casas et al., 2010) (Figuras 5,6 y 7).

\section{Determinación de la CEM50}

Para determinar la CEM50, los complejos ovocito-células del cúmulus (COCs) se incubaron con diferentes concentraciones, (control, 12.5, 25 y 50 $\mu \mathrm{M}$ de PFOS en medio TCM-199). Después de 44h de incubación los ovocitos se denudaron y se lavaron con 
PBS. Posteriormente se realizó una doble tinción con MTT-Hoechst siguiendo los criterios de evaluación especificados anteriormente.

La CEM50 se determinó utilizando la regresión lineal binomial Probit, incluida en el paquete estadístico SPSS (FDA,USA) y los gráficos se realizaron utilizando el paquete estadístico Origin Lab 9.

\section{Determinación del efecto de PFOS en las uniones intercelulares comunicantes y en la maduración de ovocitos porcinos.}

Se utilizó la metodología reportada por Sasseville y Thomas (Sasseville et al., 2009; Thomas et al., 2004). Los COCs se incubaron en las condiciones arriba descritas en presencia de la CIM50 de PFOS y como control positivo se utilizó el inhibidor de uniones comunicantes Carbenoxolona di sódica (Carbexonolone disodium salt C4790$1 G$ Sigma Aldrich).

Pasadas 4.5, 8.5, 22 y 44h los ovocitos incubados con la concentración de inhibición de la maduración $50(10 \mu \mathrm{M})$ de PFOS, fueron transferidos a una solución recién preparada

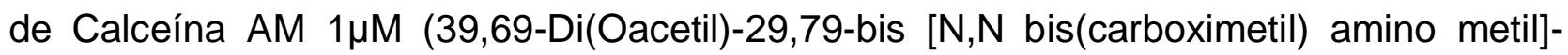
fluoresceína, tetraacetoxi metil éster; Molecular Probes, Life Technologies) en medio PBS libre de proteínas y rojo fenol para evitar interferencia en la medición de fluorescencia, y se incubaron por un periodo de $15 \mathrm{~min}$. Posteriormente los ovocitos se transfirieron nuevamente a los medios de cultivo iniciales durante $25 \mathrm{~min}$ para permitir el paso de la tinción de las células del cúmulus al ovocito.

Pasado ese tiempo de incubación, los COCs se lavaron 3 veces para eliminar el exceso de colorante y se realizó el análisis de fluorescencia en un microscopio Confocal a 488nm a 200x, para determinar el paso de Calceína a los ovocitos madurados en presencia de un medio de la $\mathrm{CEM}_{50}$ encontrada para PFOS. 


\section{Extracción del RNA total de COCs.}

Los COCs se incubaron en las condiciones arriba descritas en presencia de un medio de la CEM50 de PFOS y un control. Pasadas 4.5, 8.5 y 44h de incubación los ovocitos se lavaron 3 veces en PBS, se congelaron en $\mathrm{N}_{2}$ y se guardaron en congelación a $-70^{\circ} \mathrm{C}$ hasta su procesamiento. El RNA total de aproximadamente $100 \mathrm{COCs}$ por muestra se extrajo usando el kit SV Total RNA Isolation System de Promega siguiendo las indicaciones del fabricante.

\section{RT-PCR}

El RNA aislado de los COCs, fue retrotranscrito y la PCR semicuantitativa se llevó a cabo utilizando los primers reportados para las conexinas $C x 43,45$ y 60 según (Santiquet et al., 2013). Como control se utilizaron los genes constitutivos $\beta$-actina y $\mathrm{H}_{2} \mathrm{~A}$ que se diseñaron con el programa primer3 de la manera descrita por Bonilla y del Mazo (Bonilla|y| del Mazo, 2010). 


\section{Resultados.}

\section{Determinación de la viabilidad con el diluyente durante la maduración de ovocitos.}

Se realizaron 3 ensayos por duplicado con el control diluyente (DMSO) para descartar el efecto del mismo en la viabilidad utilizando los porcentajes de DMSO equivalentes a los tratamientos utilizados con PFOS. Los tratamientos, incluyeron: Control y DMSO a concentraciones $0.06,0.12$ y $0.25 \%$.

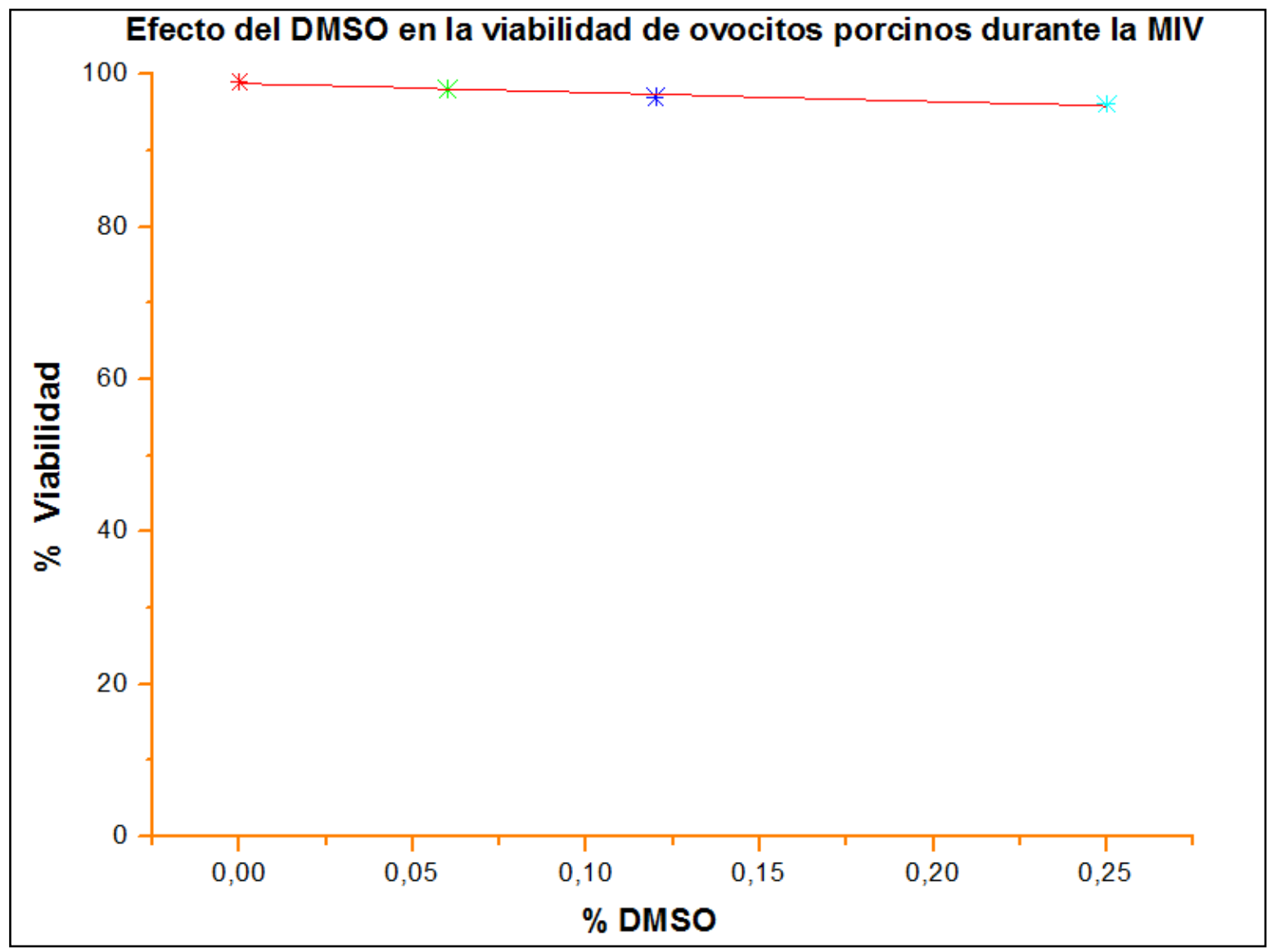

Figura 5. El DMSO se utilizó en los porcentajes finales cuando se preparan las concentraciones de PFOS $12.5 \mu \mathrm{M}, 25 \mu \mathrm{M}$ y $50 \mu \mathrm{M}$, los porcentajes de DMSO son $0.06 \%, 0.12 \%$ ) y $0.25 \%$ respectivamente y están representadas por los asteriscos. El análisis Anova seguido de un test de Duncan mostró que no existen diferencias significativas entre grupos. $n=3, P<0.05$ se utilizaron 60 ovocitos por tratamiento. 


\section{Determinación de la CL50 de PFOS durante la maduración de ovocitos}

Los ensayos iniciales con PFOS se realizaron con las concentraciones $100 \mu \mathrm{M}, 75 \mu \mathrm{M}$ y $50 \mu \mathrm{M}$. Después de 4 ensayos se determinó que en $75 \mu \mathrm{M}$ la viabilidad era el $0 \%$ por lo que en los siguientes ensayos se utilizaron concentraciones de $0,12.5 \mu \mathrm{M}, 25 \mu \mathrm{M}$ y $50 \mu \mathrm{M}$. La viabilidad se determinó pasadas de 42 a 44 horas de incubación y los ovocitos se tiñeron con MTT. Los resultados se observan en la Figura 6.

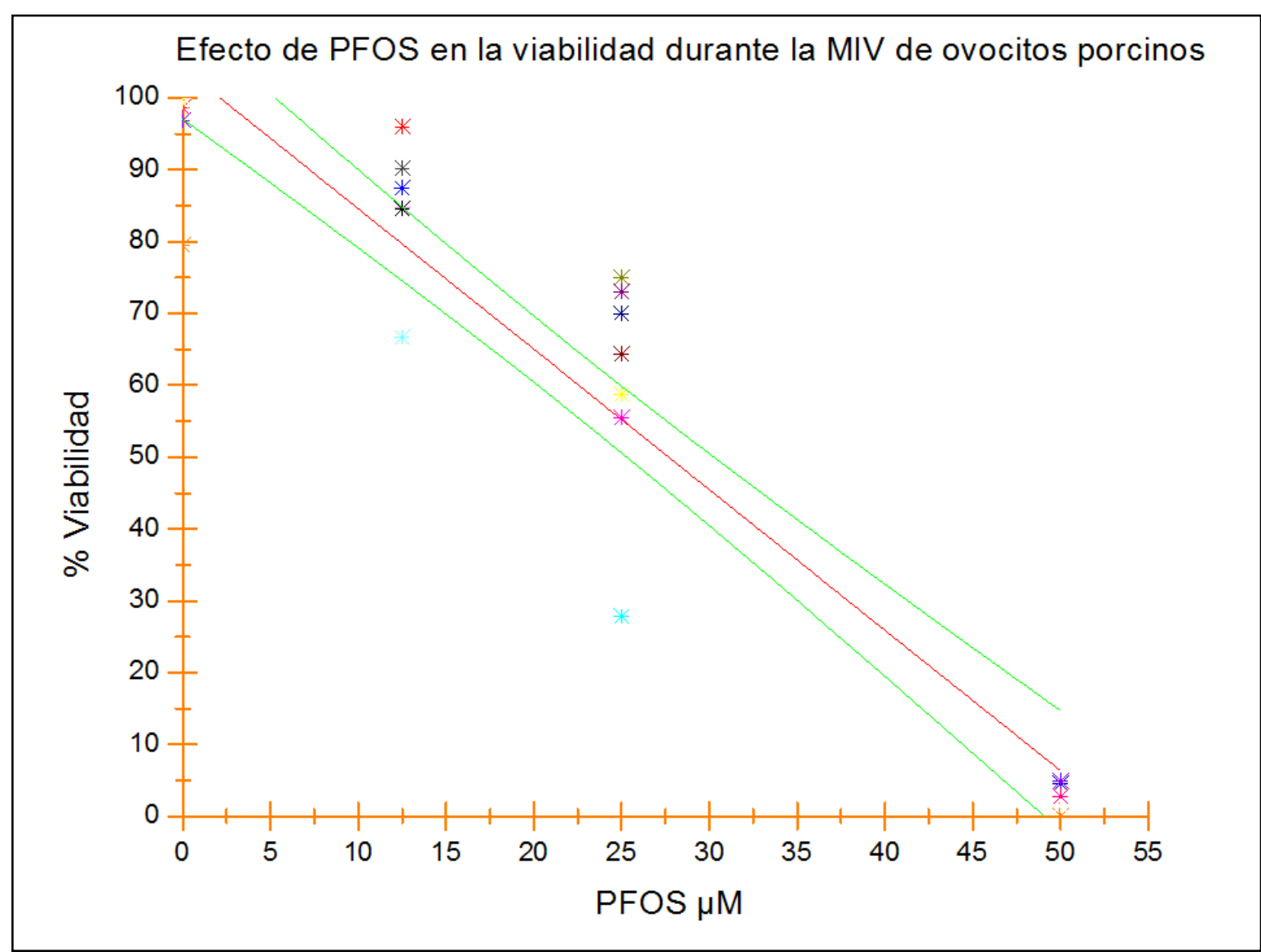

Figura 6. Se muestra la viabilidad de ovocitos porcinos expuestos a diferentes concentraciones de PFOS durante la MIV. La viabilidad obtenida en las concentraciones 12.525 y $50 \mu \mathrm{M}$ está representada por asteriscos, y cada color indica un experimento diferente. Se observa que existe una relación inversamente proporcional de la concentración de PFOS con la viabilidad. La línea roja representa la regresión lineal y las líneas verdes los intervalos de confianza. Se determinó una CL50 de $29.86 \mu \mathrm{M}$. $n=7$ y 60 ovocitos por tratamiento. Los datos se obtuvieron mediante la regresión lineal binomial Probit, incluida en el paquete estadístico SPSS (FDA, USA). Se realizó un ANOVA seguido de un test de Duncan con una $\mathrm{P}<0.05$. 
Mediante la regresión lineal binomial Probit se determinó que la CL50 de PFOS en la maduración de los ovocitos porcinos es de $29.86 \mu \mathrm{M}$ con un límite inferior de $22.72 \mu \mathrm{M}$ y un límite superior de $41.94 \mu \mathrm{M}$. El ANOVA seguido de un análisis de Test de Duncan indicó que existen diferencias significativas entre el control y las concentraciones de 25 y $50 \mu \mathrm{M}$.

\section{Determinación de la CEM50 de PFOS en ovocitos}

Para asegurar que los ovocitos evaluados en la maduración estuvieran vivos, se realizó la técnica de doble tinción de MTT-Hoechst. Con el MTT se discriminaron los ovocitos vivos (teñidos en púrpura) de los muertos (sin tinción). Los ovocitos vivos fueron teñidos con Hoechst y mediante la tinción de núcleos se evaluó el estado de maduración de los ovocitos al finalizar la incubación (Figura 7).

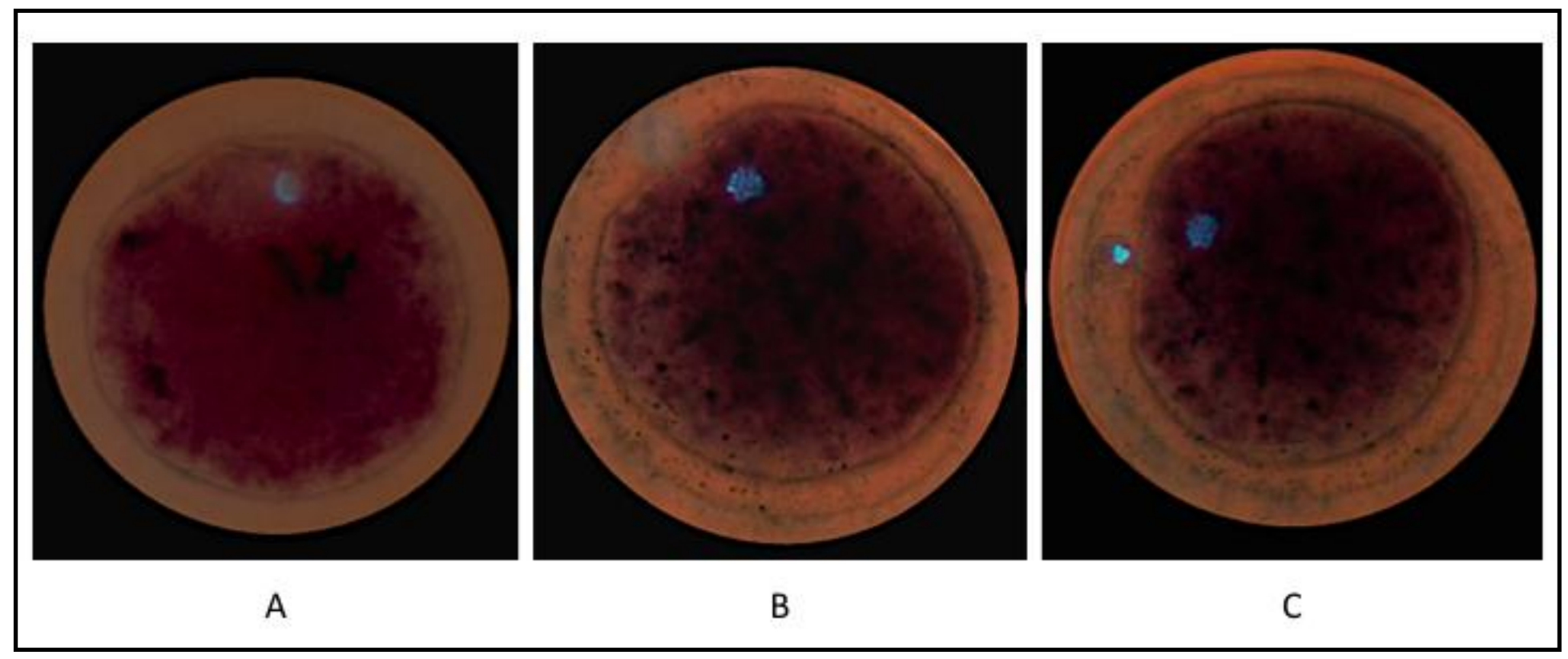

Figura 7. Se presenta ovocito en vesícula germinal ya que hay un sólo núcleo (A). El ovocito en metafase I presenta un paquete cromosómico que indica una etapa de Meiosis I (B). El ovocito en metafase II presenta un paquete cromosómico y un cuerpo polar en extrusión (C). Todos los ovocitos fueron teñidos con MTT- Hoechst y se observaron con Epifluorescencia (400X). 
La CEM50 (Concentración de Inhibición de la maduración 50) se obtuvo después de evaluar el grado de maduración de los ovocitos teñidos con Hoechst y expuestos a 0 , 12.5, 25 y $50 \mu \mathrm{M}$ de PFOS durante 44h. Mediante la regresión lineal binomial Probit, se determinó que la CIM50 es de $23.34 \mu \mathrm{M}$ (Figura 8).

\section{CEM50 de Ovocitos Porcinos expuestos a PFOS}

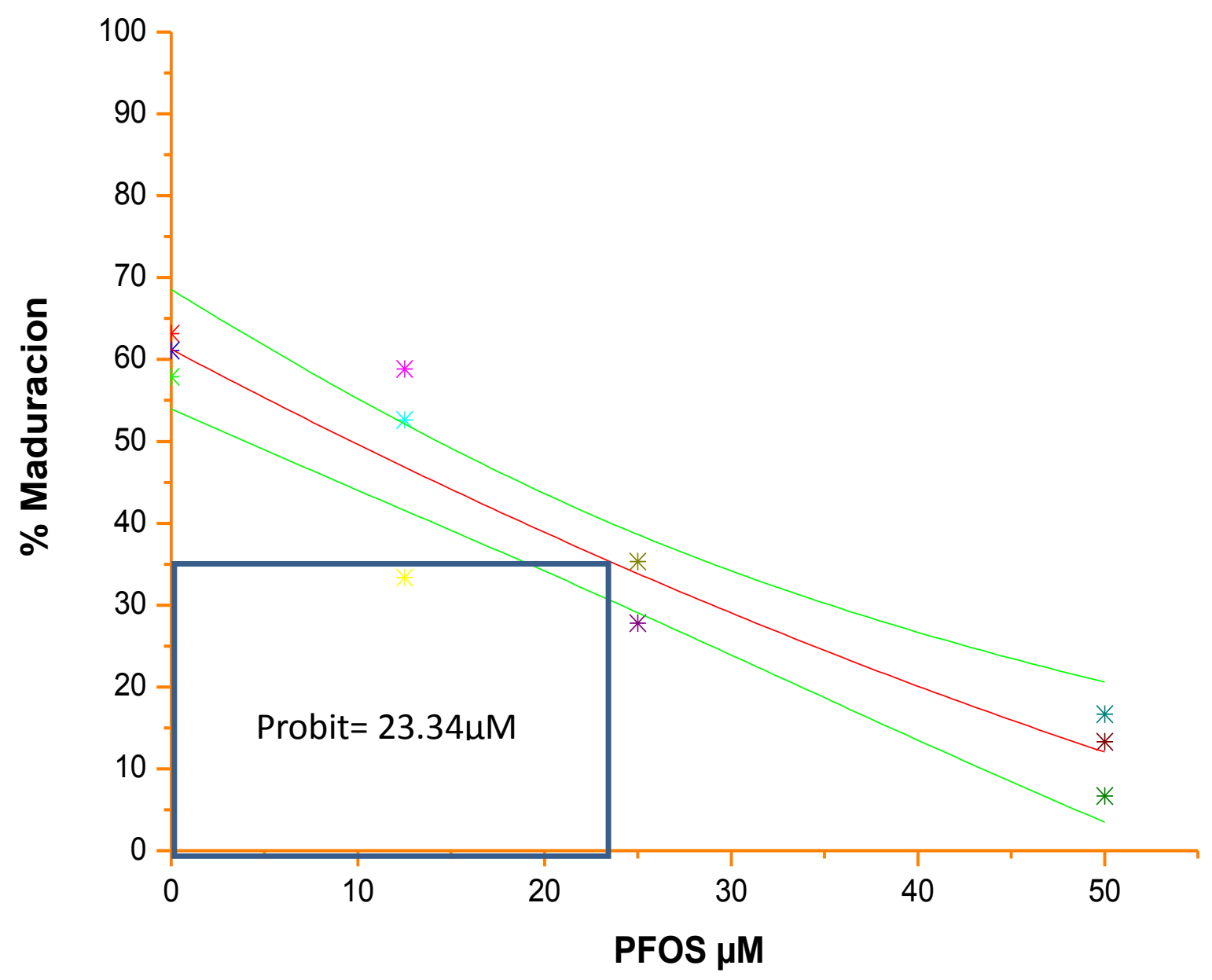

Figura 8. La $\mathrm{CIM}_{50}$ obtenida fue de $9.93 \mu \mathrm{M}$. Las concentraciones 12.525 y $50 \mu \mathrm{M}$ están representadas por ${ }^{* * *}$ respectivamente. La línea roja representa la regresión lineal y las líneas verdes los intervalos de confianza. $n=3$ experimentos y 60 ovocitos por tratamiento. El análisis por ANOVA seguido de un Test de Duncan con una $\mathrm{P}<0.05$ indicaron una diferencia significativa entre 25 y $50 \mu \mathrm{M}$ con respecto al control. 
Los porcentajes de maduración permiten observar un efecto dosis-respuesta es decir, conforme aumenta la concentración de PFOS disminuye la maduración de los ovocitos. Con respecto al control, cuyo porcentaje de maduración usualmente es del $70 \%$, y después de normalizar los datos, se observó que en las concentraciones de 12.5, 25, y $50 \mu \mathrm{M}$ la maduración se inhibió en un 55, 60, y $85 \%$ respectivamente.

\section{Evaluación de $10 \mu \mathrm{M}$ de PFOS en las uniones comunicantes a diferentes tiempos de incubación}

Las uniones comunicantes en los COCs se evaluaron mediante tinción con calceína utilizando la CEM50/2 obtenida con PFOS y como control positivo la carbenoxolona di sódica a la concentración reportada como inhibitoria para uniones comunicantes de

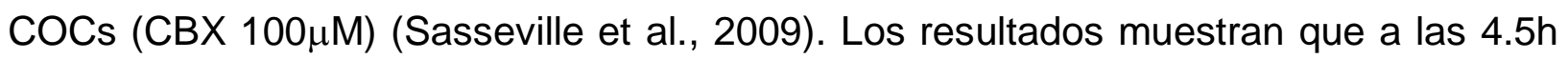
de incubación la calceína se encuentra en los ovocitos de los COCs control $(0 \mu \mathrm{M})$, mientras que en los ovocitos de los COCs expuestos a CBX $(100 \mu \mathrm{M})$ y PFOS $(10 \mu \mathrm{M})$ no se detecta calceína en su interior, lo anterior indica que las uniones comunicantes son funcionales en los COCs control $(0 \mu \mathrm{M})$ en contraste con los COCs expuestos a CBX y PFOS (Figura 9). 


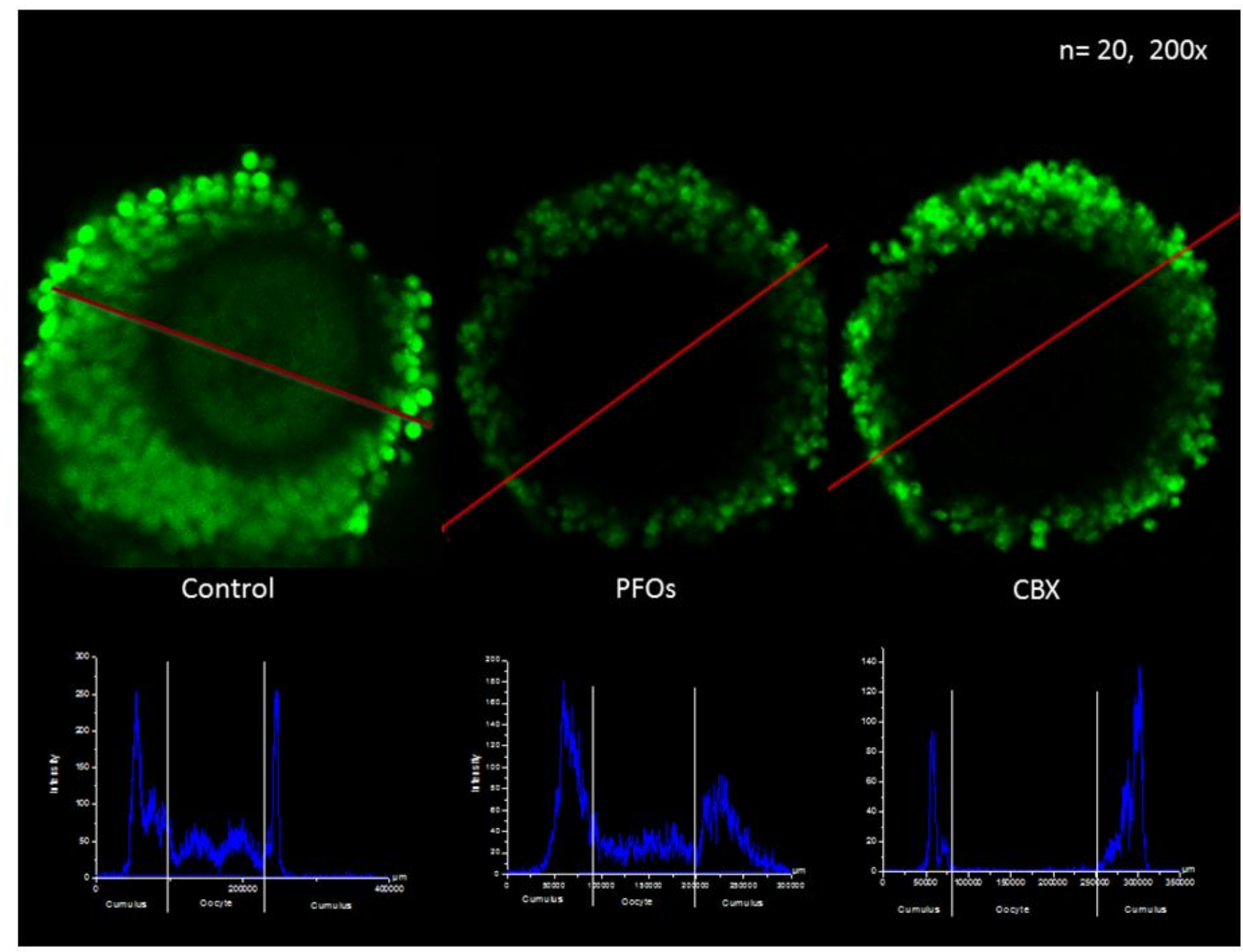

Figura 9. Se observan COCs incubados $4.5 \mathrm{~h}$ y teñidos con calceína: $(A)$ Control $(0 \mu \mathrm{M})$, la fluorescencia se presenta en células del cúmulus y ovocito. (B) COCs incubados con PFOS $(10 \mu \mathrm{M})$ presentan fluorescencia en células del cúmulus pero no en ovocito. (C) COCs incubados con CBX $(100 \mu \mathrm{M})$ se observan células del cúmulus con fluorescencia pero no en ovocito. Las gráficas representan los perfiles de intensidad de la fluorescencia en la región marcada con la línea roja. Epifluorescencia Confocal 200X. 
A las $8.5 \mathrm{~h}$ de incubación la calceína permea a los ovocitos de los COCs control $(0 \mu \mathrm{M})$, mientras que en los ovocitos de los COCs expuestos a CBX $(100 \mu \mathrm{M})$ y PFOS $(10 \mu \mathrm{M})$ no hay presencia de calceína en los ovocitos. Estos resultados muestran que en este tiempo de incubación las uniones comunicantes aún son funcionales en los COCs control $(0 \mu \mathrm{M})$ a diferencia de los COCs expuestos a CBX y PFOS (Figura 10).

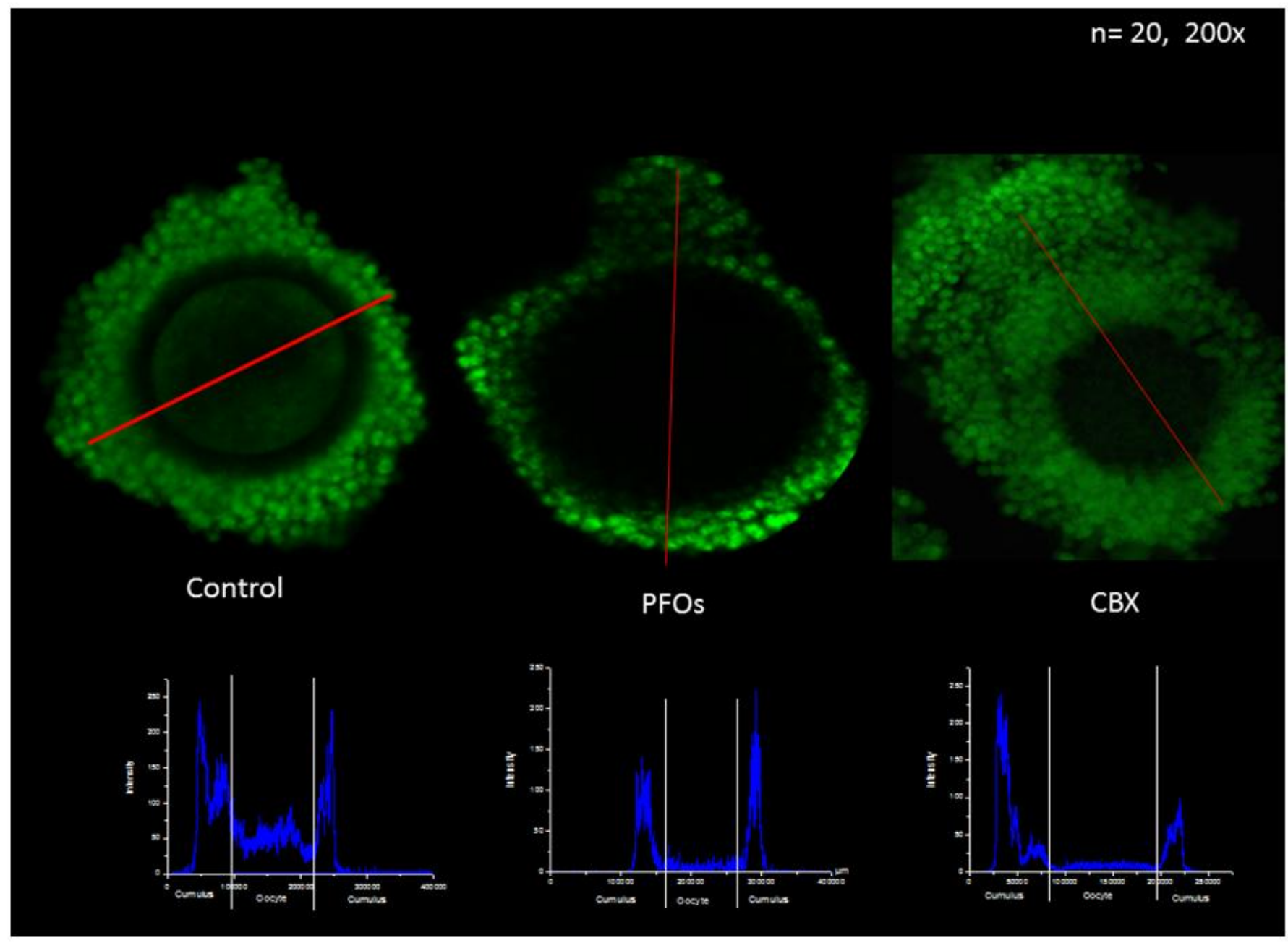

Figura 10. Se presentan los COCs incubados $8.5 \mathrm{~h}$ y teñidos con calceína: $(A)$ Control $(0 \mu \mathrm{M})$, la fluorescencia se presenta en células del cúmulus y el ovocito. (B) COCs incubados con PFOS $(10 \mu \mathrm{M})$ presenta fluorescencia en células del cúmulus pero no en el ovocito. (C) COCs incubados con CBX $(100 \mu \mathrm{M})$ se observa fluorescencia en las células del cúmulus pero no en el ovocito Las gráficas representan los perfiles de intensidad de la fluorescencia en región marcada con la línea roja sobre las células. Epifluorescencia Confocal 200X. 
A las $22 \mathrm{~h}$ de incubación, la calceína es incapaz de llegar a los ovocitos tanto de los COCs control $(0 \mu \mathrm{M})$, como de los COCs expuestos a CBX $(100 \mu \mathrm{M})$ y PFOS $(10 \mu \mathrm{M})$. En este periodo de incubación las uniones comunicantes ya no son funcionales en los COCs control debido a que el ovocito ha salido del arresto meiótico (Figura 11).

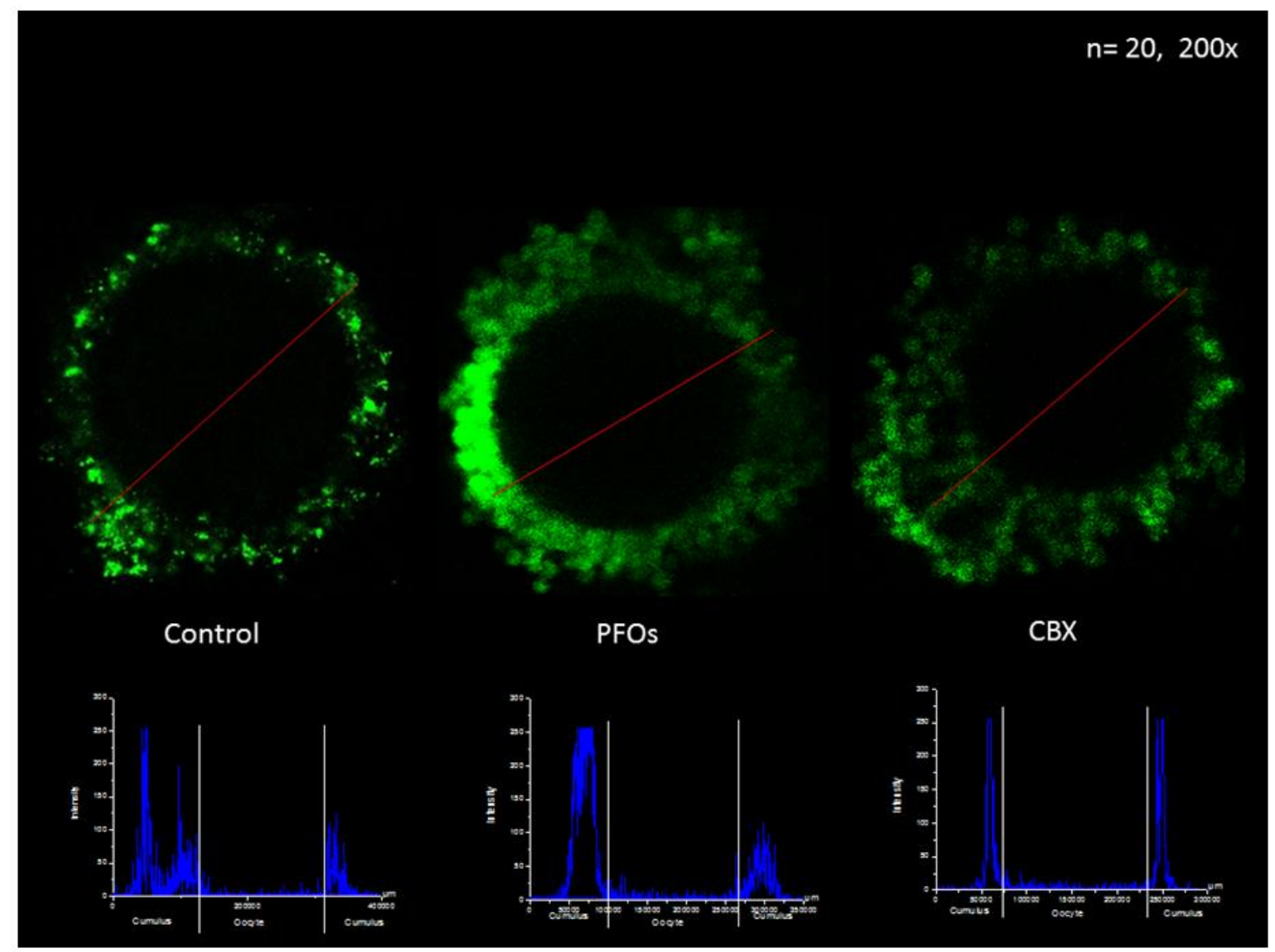

Figura 11. COCs incubados $22 \mathrm{~h}$ y teñidos con calceína: $(A)$ Control $(0 \mu \mathrm{M})$, la fluorescencia se presenta en células del cúmulus pero no es detectable en ovocito. (B) COCs incubados con PFOS $(10 \mu \mathrm{M})$ presentan fluorescencia en sólo en células del cúmulus pero no en ovocito. (C) COCs incubados con CBX $(100 \mu \mathrm{M})$ se observan la fluorescencia sólo en las células del cúmulus. Las gráficas representan los perfiles de intensidad de la fluorescencia en región marcada con la línea roja sobre las células. Epifluorescencia Confocal 200X. 
A las $44 \mathrm{~h}$ de incubación, tiempo en el que los ovocitos alcanzan su maduración meiótica, se observa que la calceína es incapaz de llegar a los ovocitos de los COCs en todas las condiciones de exposición. En este momento de la maduración las uniones comunicantes ya no son funcionales debido a que el ovocito ha salido del arresto meiótico y continuado con su maduración nuclear (Figura 12).

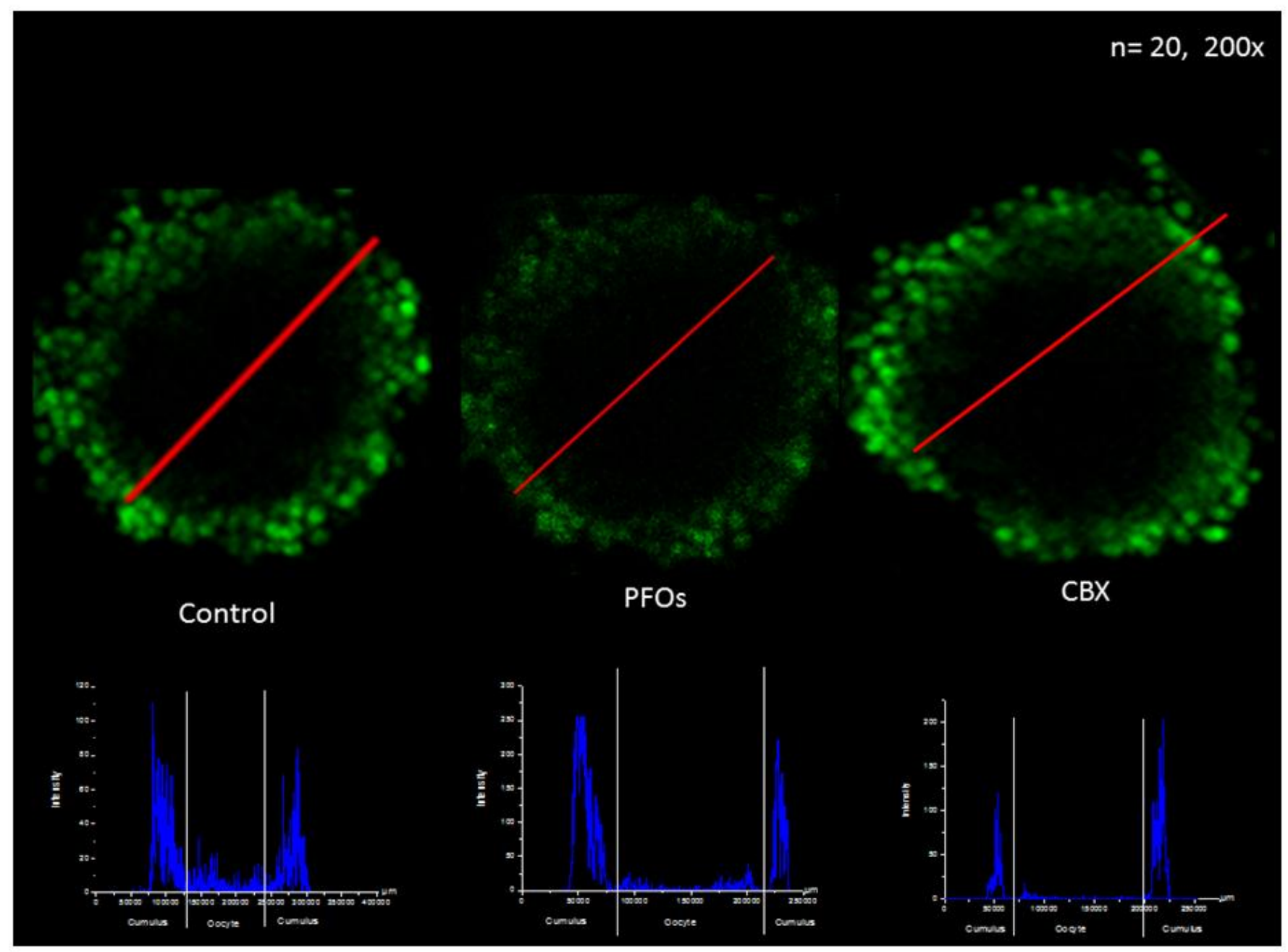

Figura 12. Se observa el patrón de fluorescencia de los COCs incubados $44 \mathrm{~h}$ y teñidos con calceína: (A) Control $(0 \mu \mathrm{M})$, la fluorescencia se presenta en células del cúmulus pero no es detectable en ovocito. (B) COCs incubados con PFOS $(10 \mu \mathrm{M})$ presentan el mismo patrón de fluorescencia que en control. (C) COCs incubados con CBX $(100 \mu \mathrm{M})$ presentan mismo patrón de fluorescencia que las otras 2 condiciones. Las gráficas representan los perfiles de intensidad de la fluorescencia en región marcada con la línea roja sobre las células. Epifluorescencia Confocal 200X. 


\section{Análisis de expresión Génica de las Conexinas 43, 45 y 60 en COCs Porcinos}

La amplificación del cDNA se realizó utilizando los cebadores para las Cx 43, 45 y 60 diseñados por Santiquet et al., (2013), los cebadores de los genes constitutivos se diseñaron de acuerdo al programa Primer3 utilizando las secuencias obtenidas para los transcritos de $\beta$-actina y $\mathrm{H}_{2} \mathrm{~A}$ de la base de datos ensemble. Los productos de amplificación y temperaturas de alineamiento se muestran en la tabla 1.

Tabla 1. Secuencia de cebadores utilizados, productos de amplificación y temperaturas de alineamiento.

\begin{tabular}{|c|c|c|c|}
\hline Gen & Secuencias 5'-3' F y R & Producto PCR & $\mathrm{T} \circ \mathrm{C}$ \\
\hline \multirow[t]{2}{*}{$\mathrm{H} 2 \mathrm{~A}$} & AGTTTCCTGTGGGTCGAGTG & 162 & 56 \\
\hline & TGCGAGTCTTCTTGTTGTCG & & \\
\hline \multirow[t]{2}{*}{$\beta$-actina } & CGGTGAGGTACTCCAGGATG & 180 & 55 \\
\hline & GGTAAGGCTGGGAAGGACTC & & \\
\hline \multirow[t]{2}{*}{ Cx 43} & ACTGAGCCCCTCCAAAGACT & 191 & 55 \\
\hline & GCTCGGCACTGTAATTAGCC & & \\
\hline \multirow[t]{2}{*}{ Cx 45} & TGTATGGCTTCCAAGTCCACCCAT & 144 & 55 \\
\hline & TAAGCAGTAGGCAAAGGCCTGTCA & & \\
\hline \multirow[t]{2}{*}{$C \times 60$} & GGCATTGAGGATGAAAGGGG & 378 & 55 \\
\hline & GAAGCCATTTGTTGTACCTAGCC & & \\
\hline
\end{tabular}

El análisis de la expresión de las conexinas mediante RT-PCR, muestra que a las $4.5 \mathrm{~h}$ de incubación no existen diferencias significativas en la expresión de estos genes en los COCs expuestos a PFOS con respecto a los del control $(0 \mu \mathrm{M})$ (figuras 20 y 21 ). 


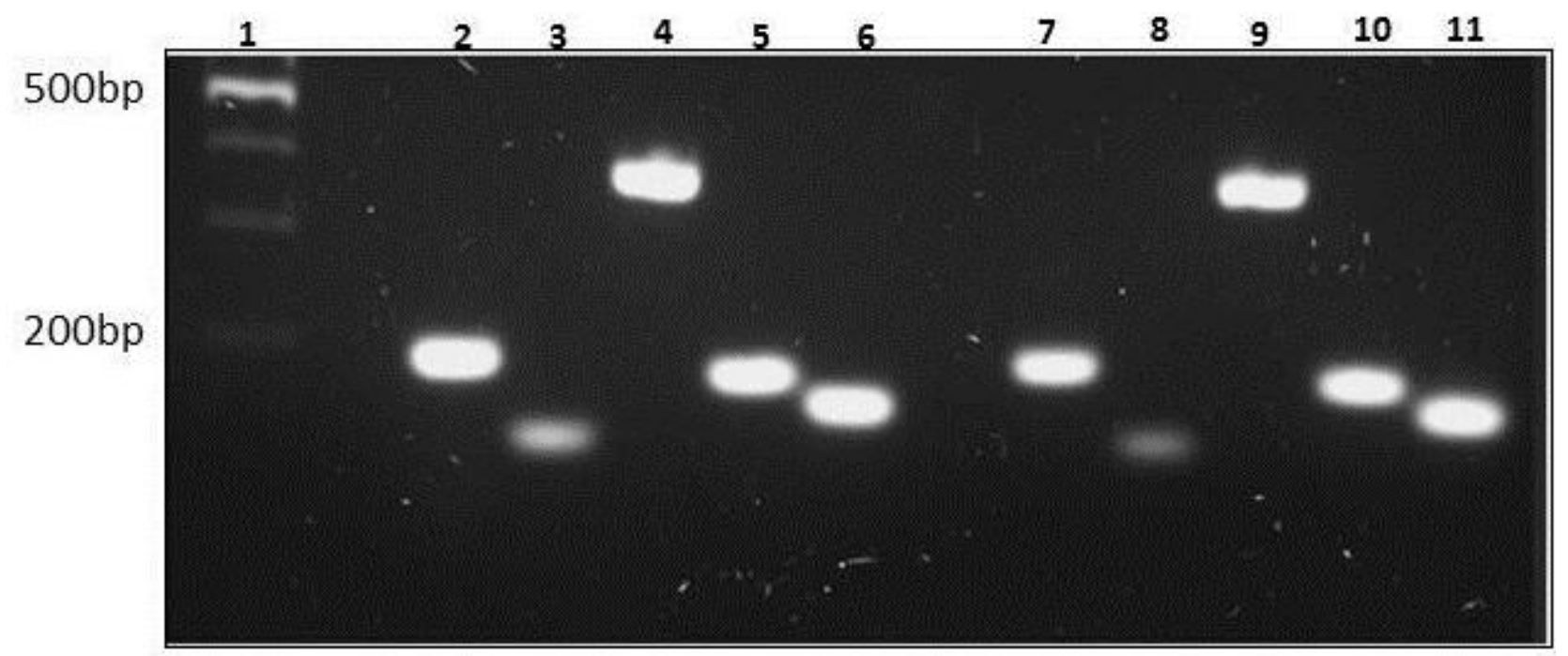

Figura 20. Electroforesis en gel de agarosa al 2\%. Carril 1 Marcador de PM (M) 100pb. Carriles 2 a 6 se muestra la expresión de los genes de $\mathrm{Cx} 43,45,60, \beta$ Actina y $\mathrm{H}_{2} \mathrm{~A}$ a partir del cDNA de los COCs control $(0 \mu \mathrm{M})$. En los carriles 7 a 11 se muestra la expresión de los genes de Cx 43, 45, 60, $\beta$-actina y $\mathrm{H}_{2} \mathrm{~A}$ a partir del cDNA de los COCs expuestos a PFOS $10 \mu \mathrm{M}$ durante $4.5 \mathrm{~h}$.

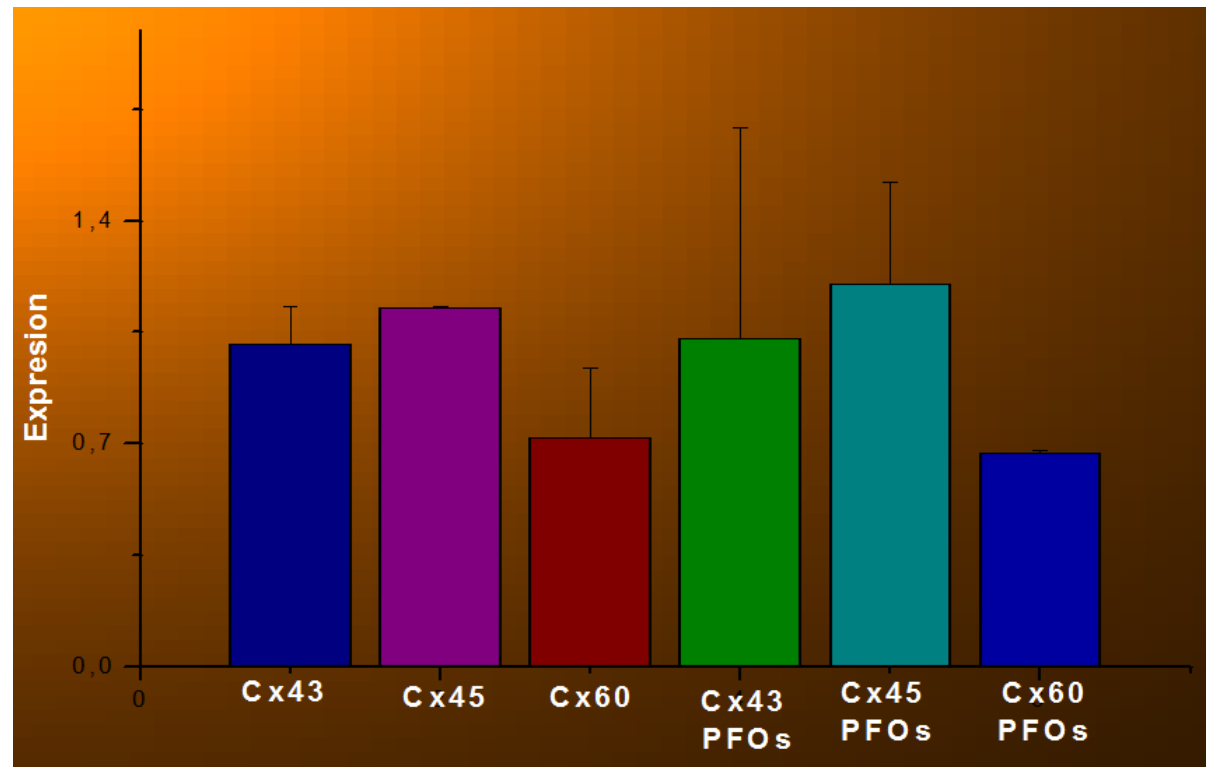

Figura 21. Análisis densitométrico a las $4.5 \mathrm{~h}$ para los genes $C x 43,45$ y 60 , y normalizado con los genes constitutivos $\beta$-actina y $\mathrm{H}_{2} \mathrm{~A}$. Se realizó un Anova seguido de un test de Duncan y no se encontraron diferencias significativas respecto a ninguno de los genes constitutivos ni de las conexinas $n=3 \quad P<0.05$. 
El análisis de la expresión de las conexinas mediante RT-PCR, muestra que a las $8.5 \mathrm{~h}$ de incubación no existen diferencias significativas en la expresión de los genes en los COCs expuestos a PFOS $(10 \mu \mathrm{M})$ con respecto a los del Control $(0 \mu \mathrm{M})$ (figuras 22 y 23).

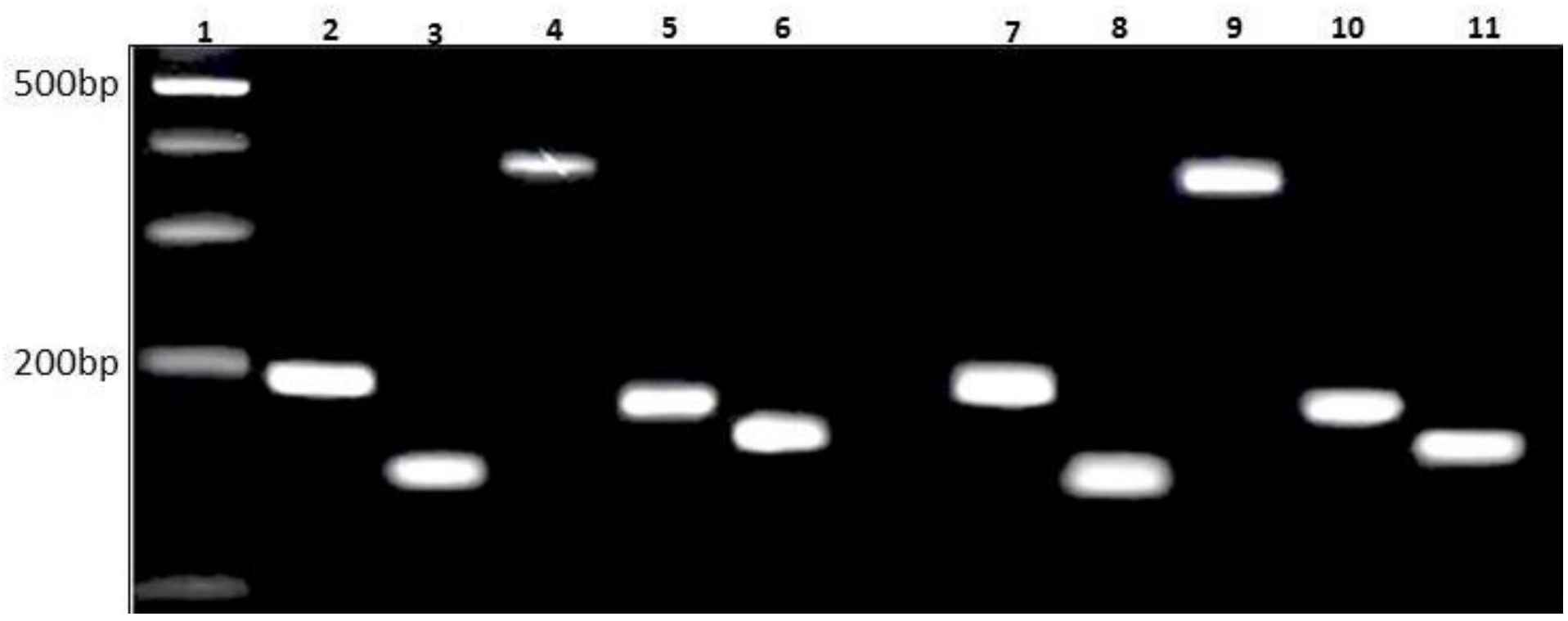

Figura 22.Electroforesis en gel de agarosa al 2\%. Carril 1 Marcador de PM 100pb. Carriles 2 a 6 se muestra la expresión de los genes de $\mathrm{Cx} 43,45,60, \beta$ Actina y $\mathrm{H}_{2} \mathrm{~A}$ a partir del cDNA de los COCs control. En los carriles 7 a 11 se muestra la expresión de los genes de $C x 43,45,60, \beta-$ Actina y $\mathrm{H}_{2} \mathrm{~A}$ a partir del cDNA de los COCs expuestos a PFOS $10 \mu \mathrm{M}$ durante 8.5h. 


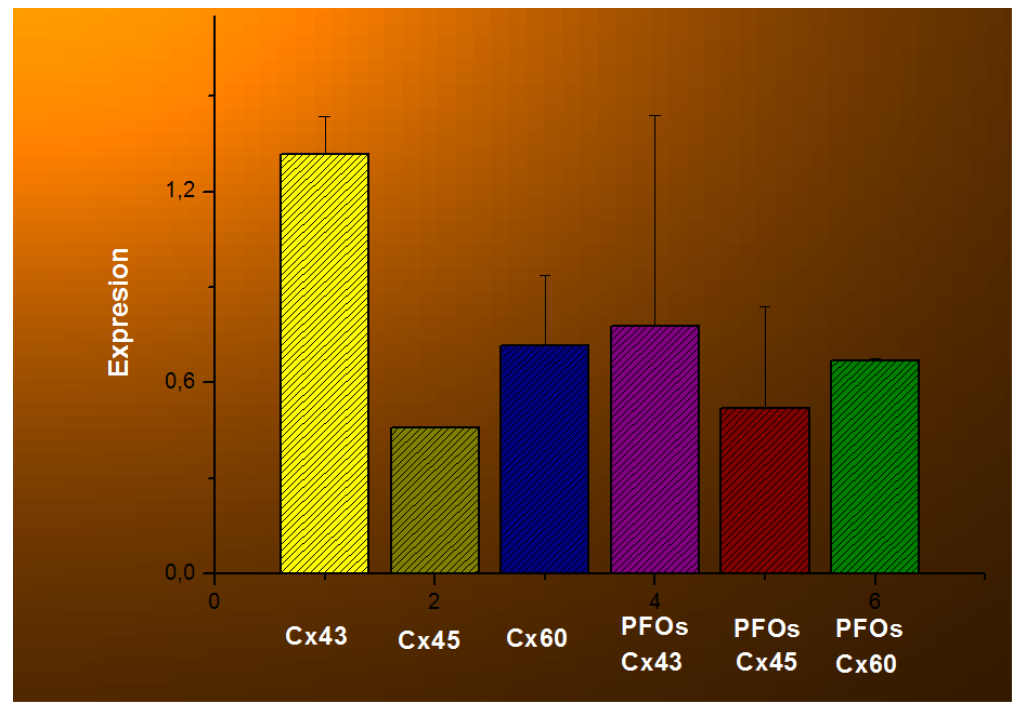

Figura 23. Análisis densitométrico a las $8.5 \mathrm{~h}$ para los genes $C x 43,45$ y 60 , y normalizado con los genes constitutivos $\beta$-actina y H2A. Se realizó un Anova seguido de un test de Duncan y no se encontraron diferencias significativas respecto a ninguno de los genes constitutivos ni de las conexinas $n=3$ $\mathrm{P}<0.05$.

A las 44h de incubación, tiempo en que sucede la maduración meiótica, se observa que la expresión transcripcional se abate tanto en los COCs control como en los expuestos a PFOS

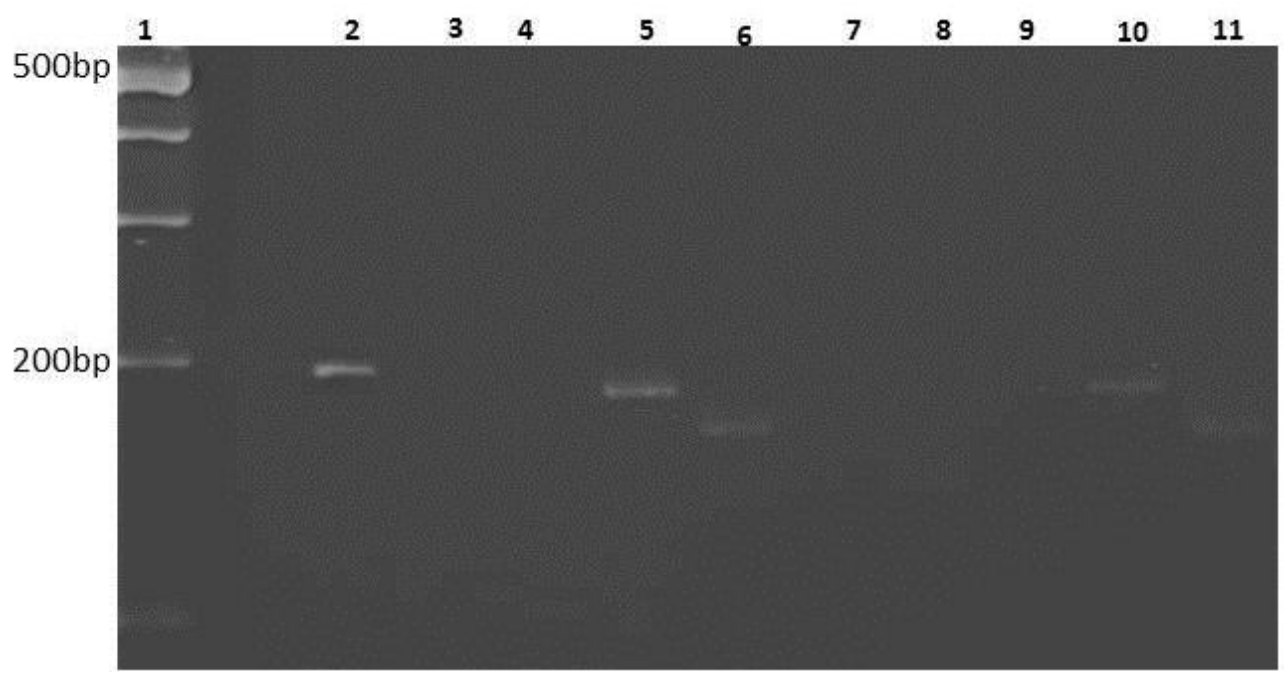

Figura 24: Electroforesis en gel de agarosa al 2\%. Carril 1 Marcador de PM 100pb. Carriles 2 se muestra a partir del cDNA de los COCs control una ligera expresión del gen de la Cx43, mientras que la expresión de los otros genes no es posible detectarla. En los carriles 5,6 y 10, 11 se detecta una ligera expresión de los genes constitutivos. No se detectó la expresión de ninguno de los genes de los COCs de las demás conexinas control y expuestos a PFOS $10 \mu \mathrm{M}$ durante 


\section{Discusión}

Los compuestos orgánicos fluorados (COFs) o productos químicos perfluorados constituyen un grupo de sustancias utilizadas ampliamente a nivel industrial. El sulfonato de perfluorooctano (PFOS) pertenece a este grupo de compuestos y es además el producto de degradación de numerosos COFs. Se sabe que las principales vías de exposición a PFOS son por ingesta, inhalación y contacto dérmico, aunque la ingesta es el principal medio a través del cual se absorbe PFOS y se transporta en la sangre unido a la albúmina, siendo capaz de atravesar barreras como la placentaria y la hematoencefálica (Austin et al., 2003; Inoue et al., 2004; Wang et al., 2011). No obstante que el PFOS se elimina por vía renal, se han encontrado concentraciones de este compuesto, tanto en suero de gente expuesta como no expuesta, que va desde 500- $2000 \mathrm{ng} / \mathrm{ml}$ (Olsen et al., 2007) hasta $13 \mu \mathrm{g} / \mathrm{ml}$, es decir $26 \mu \mathrm{M}$ (Slotkin et al., 2008) También se han detectado concentraciones de $1.3 \mathrm{ppm}$ en órganos como riñón de ternera (Kowalczyk et al., 2013) y de $0.1-10 \mathrm{mg} / \mathrm{kg}$ en ratas expuestas a este xenobiótico (Austin et al., 2003).

\section{Determinación de la viabilidad con el diluyente durante la maduración de ovocitos}

Los experimentos para probar el efecto del diluyente (DMSO) demostraron que este no afecta la viabilidad. Se ha reportado que el $0.1 \%$ de DMSO no tiene efectos en la FIV utilizando el modelo porcino (Campagna et al., 2002). En este caso no hubo efecto con la concentración más alta que corresponde a un $0.25 \%$. 


\section{Determinación de la CL50 de PFOS durante la maduración de ovocitos}

Se determinó que la CL50 para COCs porcinos durante la maduración in vitro es de $29.86 \mu \mathrm{M}$. Esta concentración es similar a la concentración más alta reportada en plasma de trabajadores expuestos que fue de $26 \mu \mathrm{M}$ o $13 \mu \mathrm{g} / \mathrm{ml}$ (Slotkin et al., 2008) Por lo que este modelo in vitro puede tomarse como referencia para futuros estudios del efecto de PFOS en la maduración de ovocitos y problemas relacionados con la fertilidad.

\section{Determinación de la CEM50 de PFOS en ovocitos}

La concentración de efecto sobre la maduración se realizó mediante la doble tinción con MTT y Hoechst lo que permitió determinar 2 parámetros al mismo tiempo: viabilidad y estado de maduración. Los resultados indican que la CEM50 obtenida es de $23.34 \mu \mathrm{M}$ y que a la mitad de esta concentración $(10 \mu \mathrm{M})$ el efecto es una inhibición en la maduración de los ovocitos. Además, la CEM50/2 se encuentra dentro del rango de las concentraciones reportadas en fluido folicular de población no expuesta y con problemas de fertilidad. En el estudio de Governini et al. (2011) se reporta una correlación en la que conforme aumenta la concentración de PFCs del fluido folicular del que fueron recuperados los ovocitos, disminuye la capacidad para ser fertilizados. Este trabajo reporta una concentración de PFCs de $15 \mathrm{ng} / \mathrm{ml}$, que si solamente fuera de PFOS correspondería a una concentración de $3 \mu \mathrm{M}$, asimismo existen evidencias que mencionan al PFOS como causa de una reducción en la fecundidad en mujeres, y que los niveles de exposición anteriormente mencionados son comunes en países desarrollados (Fei et al., 2009). 


\section{Efecto de la CEM50/2 de PFOS en las uniones comunicantes en diferentes tiempos de incubación}

Las uniones comunicantes o conexinas son canales transmembranales que comprenden proteínas que median la permeabilidad intercelular y la comunicación. Estas son muy importantes para el ovocito y las células del cúmulus en las primeras etapas ya permiten la comunicación directa y el paso de una variedad de iones inorgánicos y pequeñas moléculas, incluyendo moléculas de señalización tales como cAMP y inostiol-3-fosfato, aminoácidos, nucleótidos, vitaminas, glucosa y que permiten que el ovocito permanezca en arresto meiótico o etapa de vesícula germinal (Firestone y Kapadia, 2012; Sugimoto et al., 2013).

La maduración de los ovocitos porcinos esta reportada como una de las más largas en diferentes especies de mamíferos, con una duración de aproximadamente 44horas (Abeydeera et al., 1998; Casas et al., 2010). Se ha observado que a las 4.5 y $8.5 \mathrm{~h}$ de incubación las uniones comunicantes entre las células del cúmulus y el ovocito son funcionales (Santiquet et al., 2013). Cuando se probó el efecto del PFOS en las uniones comunicantes a $10 \mu \mathrm{M}$ mediante la tinción con calceína, se demostró que la fluorescencia en los COCS control $(0 \mu \mathrm{M})$ se encontraba tanto en células del cúmulus como en el ovocito, mientras que en los COCs cultivados en presencia de PFOS y CBX la fluorescencia sólo se detectó en las células del cúmulus. Lo anterior comprueba que el PFOS interrumpió la comunicación de las células del cúmulus con el ovocito. En ambos tiempos de incubación el ovocito porcino aún se encuentra en arresto meiótico y por lo mismo la comunicación entre las células del cúmulus con el ovocito es funcional lo cual se confirmó con los COCS control $(0 \mu \mathrm{M})$, en los que la calceína migró al interior del ovocito en contraste con los expuestos al perfluorado y al CBX respectivamente. 
Las observaciones realizadas en los COCs incubados durante 22 y $44 \mathrm{~h}$ coinciden con el metabolismo reportado en estos periodos de tiempo, ya que la comunicación entre ovocito y células del cúmulus desaparece debido al reinicio de la meiosis en el ovocito, y a que las uniones comunicantes entre las células del cúmulus y los ovocitos se pierden por expansión y generación de la matriz extracelular. Por lo anterior, en las observaciones de los COCs control y expuestos a PFOS y CBX no se observaron diferencias en los patrones de fluorescencia de la calceína.

\section{Análisis de Expresión Génica de las Conexinas 43, 45 y 60, a las 4.5, 8.5 y 44h.}

Una vez que se determinó por la tinción con calceína que las uniones comunicantes entre el ovocito y las células del cúmulus se interrumpen o son bloqueadas se procedió a determinar si el PFOS estaba actuando a nivel de la expresión génica de las conexinas ya que, aunque el PFOS no se ha reportado como un tóxico genético (Kawamoto et al., 2010), su acción como disruptor endócrino (Kowalczyk et al., 2013) podría influir en la expresión de estas proteínas.

En los ensayos de expresión génica que se realizaron a las $4.5 \mathrm{~h}$ y $8.5 \mathrm{~h}$, y después de normalizar la expresión de los genes constitutivos ( $\beta$-actina y $\mathrm{H}_{2} \mathrm{~A}$ ) en las condiciones control y experimental, la densitometría indica que no hay diferencias significativas en la expresión de las Cx 43, 45 y 60 para ambas condiciones. Estos resultados son consistentes con lo reportado (Santiquet et al., 2013) ya que en los tiempos iniciales de la maduración del ovocito es necesaria la presencia de conexinas y uniones comunicantes que permitan el paso de iones y moléculas como el AMPc que mantienen el arresto meiótico (Santiquet et al., 2013; Sasseville et al., 2009; Thomas et al., 2004). La inhibición de la expresión génica no es el mecanismo mediante el cual PFOS inhibe las uniones comunicantes ya que la expresión de las conexinas es similar en ambas condiciones. 
A las $44 \mathrm{~h}$ la expresión de las conexinas de los COCs es casi nula en ambas condiciones lo que coincide con lo reportado (Santiquet et al., 2013) debido a la perdida de uniones comunicantes y separación de las células por la generación de matriz extracelular a causa de la maduración nuclear del ovocito.

De acuerdo a los resultados obtenidos mediante la tinción con calceína es claro que PFOS afecta el funcionamiento de las uniones comunicantes y al parecer no es a través de la expresión de los genes de conexinas.

Se ha reportado que en los tejidos con respuesta a hormonas, la expresión, estabilidad y localización de las conexinas puede ser el resultado de las cascadas de respuesta a receptores hormonales nucleares y sus ligandos a través de mecanismos transcripcionales y no transcripcionales. El PFOS sin embargo, al ser un disruptor endocrino podría emular la actividad de la progesterona, la cual se ha reportado provoca fluctuaciones de los estados abierto y cerrado en las uniones comunicantes en respuesta a estímulos celulares extracelulares (Firestone|y| Kapadia, 2012). Igualmente otra manera de actuar del PFOS como un disruptor endócrino podría ser influyendo en la activación de cinasas y fosfatasas que produzcan fosforilaciones o desfosforilaciones en las conexinas cambiando su conformación y por lo mismo el estado abierto o cerrado, de la unión comunicante tal como se ha reportado que sucede con la Cx 43 después de un estímulo con la hormona LH (Conti et al., 2012; Russell|y| Robker, 2007; Sela-Abramovich et al., 2005).

Los resultados en este estudio muestran un efecto paradójico del PFOS en los COCs, ya que aunque las uniones comunicantes son bloqueadas, los ovocitos no maduran, ya se ha reportado que cuando las uniones comunicantes entre el ovocito y las células son bloqueadas o interrumpidas, el ovocito reanuda su maduración nuclear (SelaAbramovich et al., 2005), pero también hay trabajos que indican que para que el ovocito reanude su maduración tiene que existir una comunicación con las células del cúmulus en momentos específicos que permitan la retroalimentación en ambos tipos de células, y que son críticos para su desarrollo y fertilización (De La Fuente y Eppig, 2001). 
Es necesario que exista el diálogo molecular entre ambos tipos celulares para que se sincronice la activación del ovocito en la que parte esencial del proceso que es la compactación de la cromatina (De La Fuente et al., 2004) y la desacetilación de las histonas(Borsuk y Milik, 2005). Es posible que la interrupción de las uniones comunicantes provocada por el PFOS entre las células del cúmulus y el ovocito interrumpa esos momentos críticos de retroalimentación molecular, y con ello se explique por qué los ovocitos no maduran a pesar de estar inhibidas las uniones comunicantes. Sería necesario probar si la adición de PFOS en distintos momentos de la maduración provoca efectos diferentes. 


\section{Conclusiones y perspectivas:}

La CL50 de PFOS para los ovocitos en complejo con células del cúmulus obtenida en este trabajo es de $29.86 \mu \mathrm{M}$ la cual es muy cercana a la reportada para poblaciones expuestas que es de $26 \mu \mathrm{M}$ (Slotkin et al., 2008) por lo que puede ser tomada como un referente para futuros trabajos.

La $\mathrm{CEM}_{50}$ de maduración de ovocitos porcinos obtenida fue de $23.34 \mu \mathrm{M}$, en este proyecto se utilizó una concentración de $10 \mu \mathrm{M}$ la cual es muy cercana a la reportada para la inhibición de uniones comunicantes que es de $6 \mu \mathrm{M}$ (Hu et al., 2002) por lo que también puede ser tomada como un referente para futuros estudios.

EI PFOS es un inhibidor de las uniones comunicantes de los COCs porcinos a $10 \mu \mathrm{M}$.

EI PFOS a la CEM50/2 (10 $\mu \mathrm{M})$ no es un inhibidor de la expresión de las conexinas 43,45 y 60 .

EI PFOS es un compuesto que a bajas concentraciones puede comprometer la maduración de los ovocitos afectando la fertilidad femenina.

Es necesario realizar más estudios para determinar si la inhibición de las uniones comunicantes puede ser por fosforilación o desfosforilación de las conexinas, o cambios en su estructura y/o distribución. 


\section{Bibliografía}

Abeydeera, L.R., Wang, W.H., Prather, R.S. y Day, B.N., 1998, Maturation in vitro of pig oocytes in protein-free culture media: fertilization and subsequent embryo development in vitro. Biol Reprod 58, 1316-1320. Alexander, B.H.|y| Olsen, G.W., 2007, Bladder cancer in perfluorooctanesulfonyl fluoride manufacturing workers. Ann Epidemiol 17, 471-478.

Austin, M.E., Kasturi, B.S., Barber, M., Kannan, K., MohanKumar, P.S.y MohanKumar, S.M., 2003, Neuroendocrine effects of perfluorooctane sulfonate in rats. Environ Health Perspect 111, 1485-1489.

Bonilla, E.y del Mazo, J., 2010, Deregulation of the Sod1 and Nd1 genes in mouse fetal oocytes exposed to mono-(2-ethylhexyl) phthalate (MEHP). Reprod Toxicol 30, 387-392.

Borsuk, E. y Milik, E., 2005, Fully grown mouse oocyte contains transcription inhibiting activity which acts through histone deacetylation. Molecular Reproduction and Development 71, 509515.

Butenhoff, J.L., Olsen, G.W. y Pfahles-Hutchens, A., 2006, The applicability of biomonitoring data for perfluorooctanesulfonate to the environmental public health continuum. Environ Health Perspect 114, 1776-1782.

Carabatsos, M.J., Sellitto, C., Goodenough, D.A. y Albertini, D.F., 2000, Oocyte-granulosa cell heterologous gap junctions are required for the coordination of nuclear and cytoplasmic meiotic competence. Dev Biol 226, 167-179.

Casas, E., Bonilla, E., Ducolomb, Y. y Betancourt, M., 2010, Differential effects of herbicides atrazine and fenoxaprop-ethyl, and insecticides diazinon and malathion, on viability and maturation of porcine oocytes in vitro. Toxicol In Vitro 24, 224-230.

Conti, M., Hsieh, M., Zamah, A.M. y Oh, J.S., 2012, Novel signaling mechanisms in the ovary during oocyte maturation and ovulation. Mol Cell Endocrinol 356, 65-73.

Cruciani, V. y Mikalsen, S.O., 2006, The vertebrate connexin family. Cell Mol Life Sci 63, 1125-1140.

De La Fuente, R. y Eppig, J.J., 2001, Transcriptional activity of the mouse oocyte genome: companion granulosa cells modulate transcription and chromatin remodeling. Dev Biol 229, 224-236. 
De La Fuente, R., Viveiros, M.M., Burns, K.H., Adashi, E.Y., Matzuk, M.M. y Eppig, J.J., 2004, Major chromatin remodeling in the germinal vesicle (GV) of mammalian oocytes is dispensable for global transcriptional silencing but required for centromeric heterochromatin function. Dev Biol 275, 447-458.

Dragovic, R.A., Ritter, L.J., Schulz, S.J., Amato, F., Armstrong, D.T. y Gilchrist, R.B., 2005, Role of oocyte-secreted growth differentiation factor 9 in the regulation of mouse cumulus expansion. Endocrinology 146, 2798-2806.

Ericson, I., Gomez, M., Nadal, M., van Bavel, B., Lindstrom, G. y Domingo, J.L., 2007, Perfluorinated chemicals in blood of residents in Catalonia (Spain) in relation to age and gender: a pilot study. Environ Int 33, 616-623.

Eriksen, K.T., Raaschou-Nielsen, O., McLaughlin, J.K., Lipworth, L., Tjonneland, A., Overvad, K. y Sorensen, M., 2013, Association between plasma PFOA and PFOS levels and total cholesterol in a middle-aged Danish population. PLoS One 8, e56969.

Fei, C., McLaughlin, J.K., Lipworth, L. y Olsen, J., 2009, Maternal levels of perfluorinated chemicals and subfecundity. Hum Reprod 24, 12001205.

Firestone, G.L. y Kapadia, B.J., 2012, Minireview: regulation of gap junction dynamics by nuclear hormone receptors and their ligands. Mol Endocrinol 26, 1798-1807.

Gilchrist, R.B., Lane, M. y Thompson, J.G., 2008, Oocyte-secreted factors: regulators of cumulus cell function and oocyte quality. Hum Reprod Update 14, 159-177.

Gilchrist, R.B., Ritter, L.J. y Armstrong, D.T., 2004, Oocyte-somatic cell interactions during follicle development in mammals. Anim Reprod Sci 82-83, 431-446.

Gittens, J.E. Kidder, G.M., 2005, Differential contributions of connexin37 and connexin43 to oogenesis revealed in chimeric reaggregated mouse ovaries. J Cell Sci 118, 5071-5078.

Goldberg, G.S., Valiunas, V. y Brink, P.R., 2004, Selective permeability of gap junction channels. Biochim Biophys Acta 1662, 96-101.

Governini, L., Orvieto, R., Guerranti, C., Gambera, L., De Leo, V. y Piomboni, P., 2011, The impact of environmental exposure to perfluorinated compounds on oocyte fertilization capacity. J Assist Reprod Genet 28, 415-418.

Guruge, K.S., Taniyasu, S., Yamashita, N., Wijeratna, S., Mohotti, K.M., Seneviratne, H.R., Kannan, K., Yamanaka, N. y Miyazaki, S., 2005, 
Perfluorinated organic compounds in human blood serum and seminal plasma: a study of urban and rural tea worker populations in Sri Lanka. J Environ Monit 7, 371-377.

Harada, K., Inoue, K., Morikawa, A., Yoshinaga, T., Saito, N. y Koizumi, A., 2005, Renal clearance of perfluorooctane sulfonate and perfluorooctanoate in humans and their species-specific excretion. Environ Res 99, 253-261.

Hu, W., Jones, P.D., Upham, B.L., Trosko, J.E., Lau, C. y Giesy, J.P., 2002, Inhibition of gap junctional intercellular communication by perfluorinated compounds in rat liver and dolphin kidney epithelial cell lines in vitro and Sprague-Dawley rats in vivo. Toxicol Sci 68, 429436.

Hussein, T.S., Thompson, J.G. y Gilchrist, R.B., 2006, Oocyte-secreted factors enhance oocyte developmental competence. Dev Biol 296, 514-521.

Inoue, K., Okada, F., Ito, R., Kato, S., Sasaki, S., Nakajima, S., Uno, A., Saijo, Y., Sata, F., Yoshimura, Y., Kishi, R. y Nakazawa, H., 2004, Perfluorooctane sulfonate (PFOS) and related perfluorinated compounds in human maternal and cord blood samples: assessment of PFOS exposure in a susceptible population during pregnancy. Environ Health Perspect 112, 1204-1207.

Johansson, N., Eriksson, P. y Viberg, H., 2009, Neonatal exposure to PFOS and PFOA in mice results in changes in proteins which are important for neuronal growth and synaptogenesis in the developing brain. Toxicol Sci 108, 412-418.

Karrman, A., Ericson, I., van Bavel, B., Darnerud, P.O., Aune, M., Glynn, A., Lignell, S. y Lindstrom, G., 2007, Exposure of perfluorinated chemicals through lactation: levels of matched human milk and serum and a temporal trend, 1996-2004, in Sweden. Environ Health Perspect 115, 226-230.

Kawamoto, K., Oashi, T., Oami, K., Liu, W., Jin, Y., Saito, N., Sato, I. y Tsuda, S., 2010, Perfluorooctanoic acid (PFOA) but not perfluorooctane sulfonate (PFOS) showed DNA damage in comet assay on Paramecium caudatum. J Toxicol Sci 35, 835-841.

Keil, A., Hernandez-Soto, H., Noll, R.J., Fico, M., Gao, L., Ouyang, Z.|y| Cooks, R.G., 2008, Monitoring of toxic compounds in air using a handheld rectilinear ion trap mass spectrometer. Anal Chem 80, 734741.

Kidder, G.M. y Mhawi, A.A., 2002, Gap junctions and ovarian folliculogenesis. Reproduction 123, 613-620. 
Kleszczynski, K. y Skladanowski, A.C., 2011, Mechanism of cytotoxic action of perfluorinated acids. III. Disturbance in $\mathrm{Ca}(2)+$ homeostasis. Toxicol Appl Pharmacol 251, 163-168.

Kowalczyk, J., Ehlers, S., Oberhausen, A., Tischer, M., Furst, P., Schafft, H. y Lahrssen-Wiederholt, M., 2013, Absorption, distribution, and milk secretion of the perfluoroalkyl acids PFBS, PFHxS, PFOS, and PFOA by dairy cows fed naturally contaminated feed. J Agric Food Chem 61, 2903-2912.

Lau, C., Butenhoff, J.L. y Rogers, J.M., 2004, The developmental toxicity of perfluoroalkyl acids and their derivatives. Toxicol Appl Pharmacol 198, 231-241.

Liang, C.G., Huo, L.J., Zhong, Z.S., Chen, D.Y., Schatten, H. y Sun, Q.Y., 2005, Cyclic adenosine 3',5'-monophosphate-dependent activation of mitogen-activated protein kinase in cumulus cells is essential for germinal vesicle breakdown of porcine cumulus-enclosed oocytes. Endocrinology 146, 4437-4444.

Luo, Z., Shi, X., Hu, Q., Zhao, B. y Huang, M., 2012, Structural evidence of perfluorooctane sulfonate transport by human serum albumin. Chem Res Toxicol 25, 990-992.

Midasch, O., Drexler, H., Hart, N., Beckmann, M.W. y Angerer, J., 2007, Transplacental exposure of neonates to perfluorooctanesulfonate and perfluorooctanoate: a pilot study. Int Arch Occup Environ Health 80, 643-648.

Nitta, M., Yogo, K., Ohashi, M., Akiyama, M., Kunitomo, Y., Ogawa, T., Ishida-Kitagawa, N., Miyoshi, J., Sato, E. y Takeya, T., 2010, Identification and expression analysis of connexin-45 and connexin60 as major connexins in porcine oocytes. J Anim Sci 88, 3269-3279.

Olsen, G.W., Burris, J.M., Ehresman, D.J., Froehlich, J.W., Seacat, A.M., Butenhoff, J.L. y Zobel, L.R., 2007, Half-life of serum elimination of perfluorooctanesulfonate,perfluorohexanesulfonate, and perfluorooctanoate in retired fluorochemical production workers. Environ Health Perspect 115, 1298-1305.

Olsen, G.W., Hansen, K.J., Stevenson, L.A., Burris, J.M. y Mandel, J.H., 2003a, Human donor liver and serum concentrations of perfluorooctanesulfonate and other perfluorochemicals. Environ Sci Technol 37, 888-891.

Olsen, G.W., Logan, P.W., Hansen, K.J., Simpson, C.A., Burris, J.M., Burlew, M.M., Vorarath, P.P., Venkateswarlu, P., Schumpert, J.C. y Mandel, J.H., 2003b, An occupational exposure assessment of a 
perfluorooctanesulfonyl fluoride production site: biomonitoring. AlHA $\mathrm{J}$ (Fairfax, Va) 64, 651-659.

Paul, A.G., Jones, K.C. y Sweetman, A.J., 2009, A first global production, emission, and environmental inventory for perfluorooctane sulfonate. Environ Sci Technol 43, 386-392.

Prochazka, R., Nagyova, E., Brem, G., Schellander, K. y Motlik, J., 1998, Secretion of cumulus expansion-enabling factor (CEEF) in porcine follicles. Mol Reprod Dev 49, 141-149.

Russell, D.L. y Robker, R.L., 2007, Molecular mechanisms of ovulation: coordination through the cumulus complex. Hum Reprod Update 13, 289-312.

Santiquet, N., Robert, C. y Richard, F.J., 2013, The dynamics of connexin expression, degradation and localisation are regulated by gonadotropins during the early stages of in vitro maturation of swine oocytes. PLoS One 8, e68456.

Sasseville, M., Gagnon, M.C., Guillemette, C., Sullivan, R., Gilchrist, R.B. y Richard, F.J., 2009, Regulation of gap junctions in porcine cumulusoocyte complexes: contributions of granulosa cell contact, gonadotropins, and lipid rafts. Mol Endocrinol 23, 700-710.

Seacat, A.M., Thomford, P.J., Hansen, K.J., Clemen, L.A., Eldridge, S.R., Elcombe, C.R. y Butenhoff, J.L., 2003, Sub-chronic dietary toxicity of potassium perfluorooctanesulfonate in rats. Toxicology 183, 117-131. Seacat, A.M., Thomford, P.J., Hansen, K.J., Olsen, G.W., Case, M.T. y Butenhoff, J.L., 2002, Subchronic toxicity studies on perfluorooctanesulfonate potassium salt in cynomolgus monkeys. Toxicol Sci 68, 249-264.

Sela-Abramovich, S., Chorev, E., Galiani, D. y Dekel, N., 2005, Mitogenactivated protein kinase mediates luteinizing hormone-induced breakdown of communication and oocyte maturation in rat ovarian follicles. Endocrinology 146, 1236-1244.

Sela-Abramovich, S., Edry, I., Galiani, D., Nevo, N. y Dekel, N., 2006, Disruption of gap junctional communication within the ovarian follicle induces oocyte maturation. Endocrinology 147, 2280-2286.

Slotkin, T.A., MacKillop, E.A., Melnick, R.L., Thayer, K.A. y Seidler, F.J., 2008, Developmental neurotoxicity of perfluorinated chemicals modeled in vitro. Environ Health Perspect 116, 716-722.

Sohlenius, A.K., Andersson, K., Bergstrand, A., Spydevold, O. y De Pierre, J.W., 1994, Effects of perfluorooctanoic acid--a potent peroxisome proliferator in rat--on Morris hepatoma $7800 \mathrm{C} 1$ cells, a rat cell line. Biochim Biophys Acta 1213, 63-74. 
Su, Y.Q., Sugiura, K. y Eppig, J.J., 2009, Mouse oocyte control of granulosa cell development and function: paracrine regulation of cumulus cell metabolism. Semin Reprod Med 27, 32-42.

Sugimoto, M., Sasaki, S., Gotoh, Y., Nakamura, Y., Aoyagi, Y., Kawahara, T.y Sugimoto, Y., 2013, Genetic variants related to gap junctions and hormone secretion influence conception rates in cows. Proc Natl Acad Sci U S A 110, 19495-19500.

Sugiura, K., Su, Y.Q., Li, Q., Wigglesworth, K., Matzuk, M.M. y Eppig, J.J., 2010, Estrogen promotes the development of mouse cumulus cells in coordination with oocyte-derived GDF9 and BMP15. Mol Endocrinol 24, 2303-2314.

Thomas, R.E., Armstrong, D.T. y Gilchrist, R.B., 2004, Bovine cumulus celloocyte gap junctional communication during in vitro maturation in response to manipulation of cell-specific cyclic adenosine 3',5'monophosophate levels. Biol Reprod 70, 548-556.

Upham, B.L., Park, J.S., Babica, P., Sovadinova, I., Rummel, A.M., Trosko, J.E., Hirose, A., Hasegawa, R., Kanno, J. y Sai, K., 2009, Structureactivity-dependent regulation of cell communication by perfluorinated fatty acids using in vivo and in vitro model systems. Environ Health Perspect 117, 545-551.

Wang, Q., Chi, M.M., Schedl, T.|y| Moley, K.H., 2012, An intercellular pathway for glucose transport into mouse oocytes. Am J Physiol Endocrinol Metab 302, E1511-1518.

Wang, X., Li, B., Zhao, W.D., Liu, Y.J., Shang, D.S., Fang, W.G. y Chen, Y.H., 2011, Perfluorooctane sulfonate triggers tight junction "opening" in brain endothelial cells via phosphatidylinositol 3-kinase. Biochem Biophys Res Commun 410, 258-263.

Zhang, L., Ren, X.M. y Guo, L.H., 2013, Structure-based investigation on the interaction of perfluorinated compounds with human liver fatty acid binding protein. Environ Sci Technol 47, 11293-11301.

Zhang, X., Chen, L., Fei, X.C., Ma, Y.S.y Gao, H.W., 2009, Binding of PFOS to serum albumin and DNA: insight into the molecular toxicity of perfluorochemicals. BMC Mol Biol 10, 16. 


\section{Anexos}

\section{Composición de los medios de cultivo}

\section{Medio TL-HEPES-PVA}

Para lavado de complejo ovocito-células del cumulo antes del cultivo en medio de maduración.

\begin{tabular}{|c|c|c|c|c|c|}
\hline Componente & PM & $\mathrm{mM}$ & $\mathrm{g} / 1000 \mathrm{ml}$ & $\mathrm{g} / 2000 \mathrm{ml}$ & $\mathrm{g} / 500 \mathrm{ml}$ \\
\hline $\mathrm{NaCl}$ & 58.45 & 114.00 & 6.6633 & 13.326 & 3.33165 \\
\hline $\mathrm{KCl}$ & 74.55 & 3.20 & 0.2386 & 0.4772 & 0.1193 \\
\hline $\mathrm{NaH}_{2} \mathrm{PO}_{4}$ & 120.00 & 0.34 & 0.0408 & 0.0816 & 0.0204 \\
\hline $\begin{array}{l}\text { Lactato de } \\
\qquad \mathrm{Na}^{+{ }^{*}}\end{array}$ & 112.10 & 10.00 & $1.4 \mathrm{ml}$ & $2.8 \mathrm{ml}$ & $0.7 \mathrm{ml}$ \\
\hline $\mathrm{MgCl}_{2} \cdot 6 \mathrm{H}_{2} \mathrm{O}$ & 203.30 & 0.50 & 0.1017 & 0.2034 & 0.05085 \\
\hline HEPES & 238.30 & 10.00 & 2.3830 & 4.7660 & 1.1915 \\
\hline $\begin{array}{l}\text { Piruvato de } \\
\qquad \mathrm{Na}^{+}\end{array}$ & 110.00 & 0.20 & 0.0220 & 0.0440 & 0.0110 \\
\hline Sorbitol & 182.20 & 12.00 & 2.1860 & 4.3720 & 1.0930 \\
\hline $\mathrm{NaHCO}_{3}$ & 84.00 & 2.00 & 0.1680 & 0.3360 & 0.084 \\
\hline $\mathrm{CaCl}_{2} \cdot 2 \mathrm{H}_{2} \mathrm{O}^{* *}$ & 147.00 & 2.00 & 0.2940 & 0.5880 & 0.147 \\
\hline Gentamicina & 575.67 & & 0.0250 & 0.0500 & 0.0125 \\
\hline Penicilina G & 372.5 & & 0.0650 & 0.1300 & 0.0325 \\
\hline PVA & & & 0.1000 & 0.2000 & 0.0500 \\
\hline
\end{tabular}

*Solución al $60 \% \mathrm{v} / \mathrm{V}$

${ }^{* *}$ Agregar al final

Ajustar el pH a 7.3-7.4 con $\mathrm{NaOH}$ o $\mathrm{HCl} 1 \mathrm{~N}$.

Esterilizar por filtracion en membranas de $0.22 \mu \mathrm{M}$

Almacenar a $4^{\circ} \mathrm{C}$ y usarlo en un periodo de 2 a 3 semanas. 
Medio para maduración in vitro libre de proteínas para ovocitos porcinos.

TCM-199 Modificado el cual se suplementa con:

\begin{tabular}{|c|l|l|}
\hline PVA & $0.1 \%$ & $10 \mathrm{~g} / \mathrm{l}$ \\
\hline D-Glucosa & $3.05 \mathrm{mM}$ & $0.549 \mathrm{~g} / \mathrm{l}$ \\
\hline Piruvato de Sodio & $0.91 \mathrm{mM}$ & $0.1 \mathrm{~g} / \mathrm{l}$ \\
\hline Penicilina & $75 \mu \mathrm{g} / \mathrm{ml}$ & \\
\hline Estreptomicina & $50 \mu \mathrm{g} / \mathrm{ml}$ & \\
\hline
\end{tabular}

El medio se suplementa con:

\begin{tabular}{|c|c|}
\hline EGF & $10 \mathrm{ng} / \mathrm{ml}$ \\
\hline Cisteína & $0.57 \mathrm{mM}$ \\
\hline LH & $0.5 \mu \mathrm{g} / \mathrm{ml}$ \\
\hline FSH & $0.5 \mu \mathrm{g} / \mathrm{ml}$ \\
\hline
\end{tabular}

Cuando se emplea pergonal se agregan $26 \mu \mathrm{l} / \mathrm{ml}$ en lugar de FSH y LH.

Preparación de las Hormonas LH y FSH.

LH (Sigma L 5269) $50 \mu \mathrm{g} / \mathrm{ml} \times 100$

FSH (Sigma F-2293) $50 \mu \mathrm{g} / \mathrm{ml} \times 100$

Pesar $0.005 \mathrm{~g}$ de la hormona y disolver en $10 \mathrm{ml}$ de medio.

Tomar $1 \mathrm{ml}$ de esta suspensión y agregar $9 \mathrm{ml}$ de medio (dilución 10X).

Hacer alícuota de $100 \mu \mathrm{l}$.

Conservar a $-70^{\circ} \mathrm{C}$. 
Preparación del factor de crecimiento epidérmico (EGF).

EGF (Sigma E4127) en presentación de un vial con $0.1 \mathrm{mg}$.

Hacer una dilución con TCM-199 con BSA al 0.1\% para tener una concentración de $100 \mu \mathrm{g} / \mathrm{ml}$.

Tomar $10 \mu \mathrm{l}$ de esta dilución y llevar a $1000 \mu \mathrm{l}$ con TCM-199 para obtener una concentración de $1 \mu \mathrm{g} / \mathrm{ml}$.

Hacer alícuotas de $200 \mu \mathrm{l}$.

Conservar a $-70^{\circ} \mathrm{C}$. 


\section{Análisis probit para determinar la CL50}

Límites de confianza

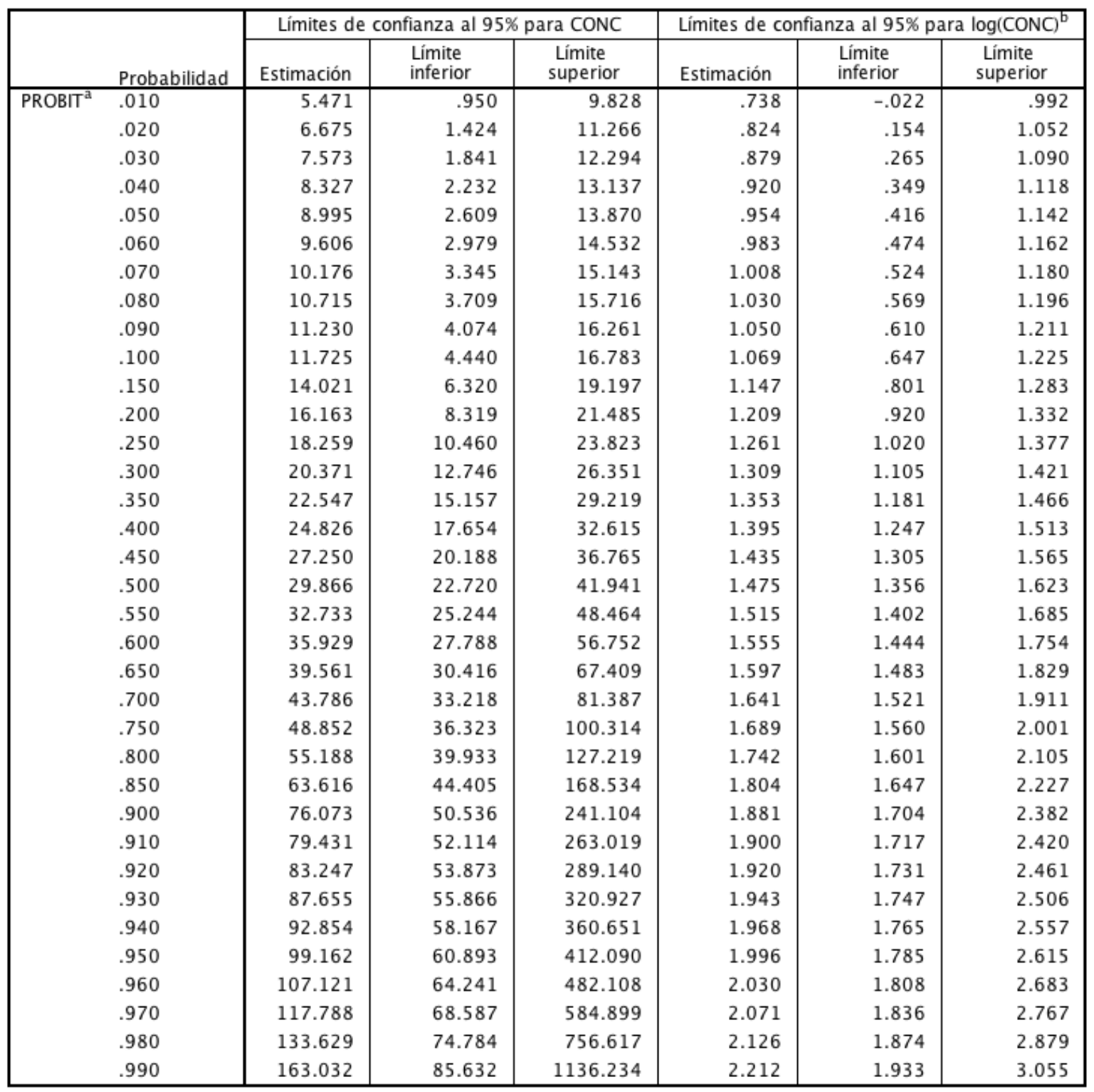

a. Se utiliza un factor de heterogeneidad.

b. Base del logaritmo $=10$. 
Análisis probit para determinar la CEM50

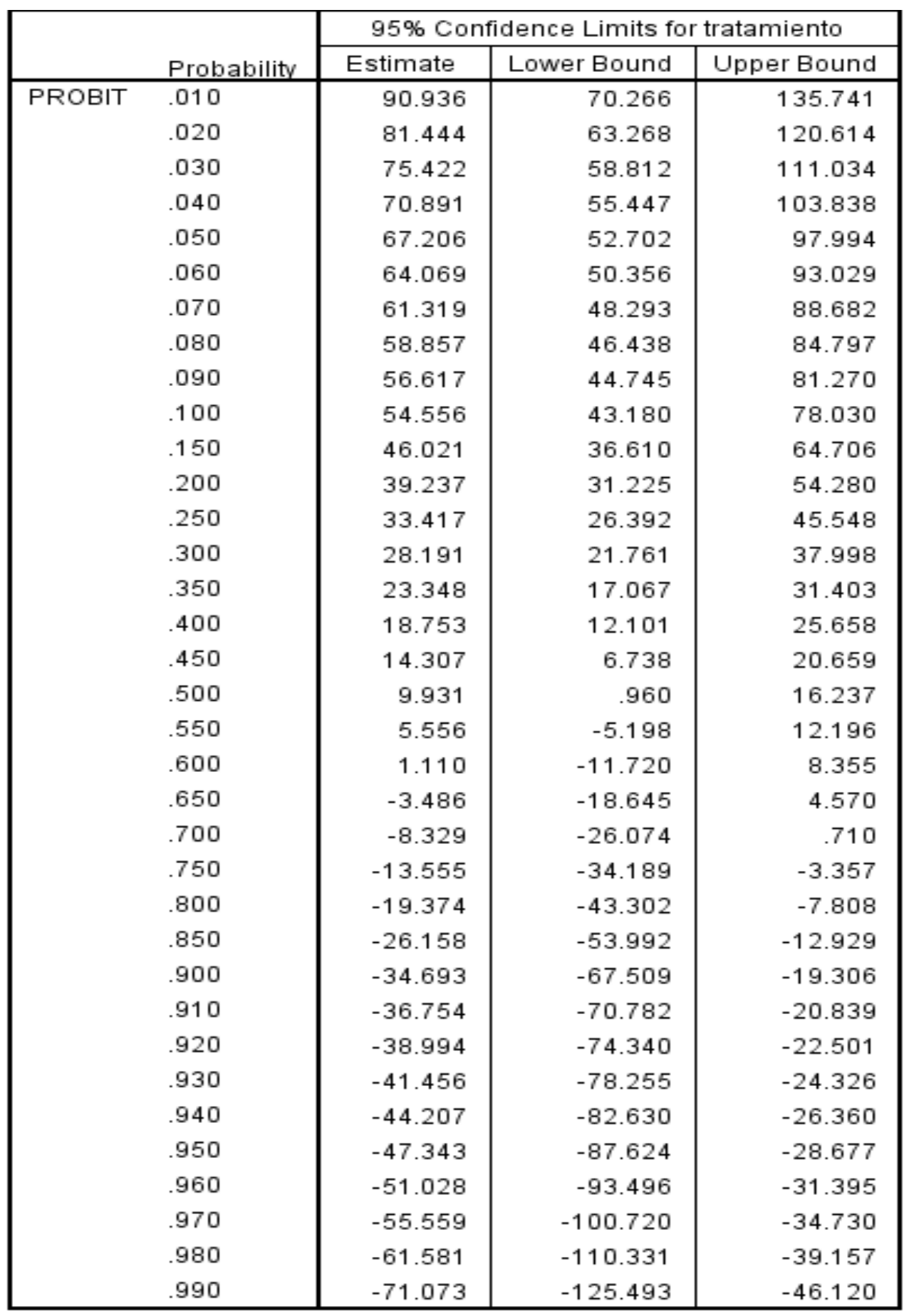

